\title{
The globally widespread genus Sulfurimonas: versatile energy metabolisms and adaptations to redox clines
}

\author{
Yuchen Han and Mirjam Perner* \\ Molecular Biology of Microbial Consortia, Biocenter Klein Flottbek, University of Hamburg, Hamburg, Germany
}

Sulfurimonas species are commonly isolated from sulfidic habitats and numerous 165 rRNA sequences related to Sulfurimonas species have been identified in chemically

OPEN ACCESS

Edited by:

Martin G. Klotz,

Queens College, The City University

of New York, USA

Reviewed by:

Kathleen Scott,

University of South Florida, USA

Stefan M. Sievert,

Woods Hole Oceanographic Institution, USA

Ken Takai,

Japan Agency for Marine-Earth

Science and Technology, Japan

*Correspondence: Mirjam Perner,

Molecular Biology of Microbial Consortia, Biocenter Klein Flottbek,

University of Hamburg,

Ohnhorststraße 18, 22609 Hamburg,

Germany

mirjam.perner@uni-hamburg.de

Specialty section:

This article was submitted to Microbial Physiology and Metabolism,

a section of the journal

Frontiers in Microbiology

Received: 11 February 2015 Accepted: 04 September 2015

Published: 16 September 2015

Citation:

Han Y and Perner M (2015) The globally widespread genus Sulfurimonas: versatile energy metabolisms and adaptations

to redox clines.

Front. Microbiol. 6:989. doi: 10.3389/fmicb.2015.00989 distinct environments, such as hydrothermal deep-sea vents, marine sediments, the ocean's water column, and terrestrial habitats. In some of these habitats, Sulfurimonas have been demonstrated to play an important role in chemoautotrophic processes. Sulfurimonas species can grow with a variety of electron donors and acceptors, which may contribute to their widespread distribution. Multiple copies of one type of enzyme (e.g., sulfide:quinone reductases and hydrogenases) may play a pivotal role in Sulfurimonas' flexibility to colonize disparate environments. Many of these genes appear to have been acquired through horizontal gene transfer which has promoted adaptations to the distinct habitats. Here we summarize Sulfurimonas' versatile energy metabolisms and link their physiological properties to their global distribution.

Keywords: Sulfurimonas, versatile metabolism, sulfur metabolism, hydrogen metabolism, horizontal gene transfer

\section{Introduction}

The epsilonproteobacterial genus Sulfurimonas was first proposed by Inagaki et al. (2003). Epsilonproteobacteria were originally considered as human and animal pathogens and known representatives included Campylobacter, Helicobacter, and Arcobacter species (Nakagawa and Takaki, 2009). However, in the last decade more and more non-pathogenic Epsilonproteobacteria have been isolated from different types of environments (Nakagawa and Takaki, 2009). Of these non-pathogenic Epsilonproteobacteria a great deal are exclusively associated with hydrothermal vent environments, e.g., Caminibacter, Nautilia, Hydrogenimonas, Thioreductor, Nitratiruptor, Nitratifractor, and Lebetimonas (cf., Campbell et al., 2006), but other species like Sulfuricurvum kujiense have so far only been detected in terrestrial environments, e.g., an underground crude-oil storage cavity at Kuji in Iwate, Japan (Engel et al., 2004; Kodama and Watanabe, 2004). In contrast, members of Sulfurospirillum, Sulfurovum, and Sulfurimonas have been found in hydrothermal vents, other marine habitats and terrestrial provinces (cf. Supplementary Table S1, Campbell et al., 2006; Nakagawa and Takaki, 2009), demonstrating their widespread occurrence. We here will focus on species of the genus Sulfurimonas, their global distribution, their versatile energy metabolisms and their adaptive abilities which may have represented one of the key features for successfully colonizing various habitats in the course of evolution.

Among the genus Sulfurimonas five species have been isolated and described: Sulfurimonas denitrificans (DSM 1251), previously named Thiomicrospira denitrificans, and S. hongkongensis 
strain AST-10 ${ }^{\mathrm{T}}$ (DSM 22096) were isolated from coastal marine sediments (Timmer-Ten Hoor, 1975; Takai et al., 2006; Cai et al., 2014), S. autotrophica strain $\mathrm{OK} 10^{\mathrm{T}}$ (DSM 16294) and S. paralvinellae strain GO25 ${ }^{\mathrm{T}}$ (DSM 17229) were isolated from sediments and polychaete nests in deep-sea hydrothermal vent fields (Inagaki et al., 2003; Takai et al., 2006), and S. gotlandica strain $\mathrm{GD}^{\mathrm{T}}$ (DSM 19862) was isolated from the pelagic redox cline in the central Baltic Sea (Grote et al., 2012; Labrenz et al., 2013). The genomes of S. denitrificans, S. autotrophica, and S. gotlandica have already been sequenced and genome sequencing of $S$. hongkongensis is currently in progress (Sievert et al., 2008b; Sikorski et al., 2010b; Grote et al., 2012; Cai et al., 2014). Based on 16S rRNA genes, a further species is phylogenetically placed within the Sulfurimonas group, namely Thiomicrospira sp. CVO (Figure 1). When Thiomicrospira sp. CVO was isolated from an oil field in Canada (Voordouw et al., 1996), the highest 16S rRNA gene similarity to an isolated strain was to that of Thiomicrospira denitrificans (96.1\% similarity) and thus it was classified into the Thiomicrospira genus (Gevertz et al., 2000). However, Thiomicrospira denitrificans had been wrongly classified into the Thiomicrospira genus (Gammaproteobacteria) and was soon after reclassified into the Sulfurimonas genus (Epsilonproteobacteria) (Takai et al., 2006). Consequently, since Thiomicrospira sp. CVO phylogenetically groups among Sulfurimonas species (Figure 1), a reclassification of this strain into the Sulfurimonas genus needs to be discussed and we here incorporate it into our discussion on Sulfurimonas species.

The top 100 hits of Blast searches with 16S rRNA gene sequences of the cultured Sulfurimonas species demonstrate the widespread occurrence of affiliates of this genus (Figure 1). Sequences have been recovered from various marine environments such as hydrothermal vent habitats, the pelagic redox cline of the Baltic and Black Sea and coastal sediments but also terrestrial habitats like oil caves, contaminated ground water or sediments and sulfidic springs or supra-glacial spring systems (Figure 1, Voordouw et al., 1996; Watanabe et al., 2000; Kodama and Watanabe, 2003; Grote et al., 2008; Glaubitz et al., 2009; Yagi et al., 2009; Gleeson et al., 2011; Headd and Summers Engel, 2014). Besides being ubiquitously found across the globe, Sulfurimonas species can also make up large proportions of the bacterial community. For example, in the pelagic redox-cline of the central Baltic Sea they made up 30\% of all cells and in plume waters and diffuse fluids of a deep-sea vent they comprised 70 and $20 \%$, respectively, of the bacterial phylotype abundance (Grote et al., 2008; Akerman et al., 2013; Perner et al., 2013a). In case of the redox-cline of the Baltic Sea, the Black Sea and the plume waters, Sulfurimonas appears to be responsible for much of the chemoautotrophic activity as measured through incorporation of radioactively labeled bicarbonate (Grote et al., 2008; Glaubitz et al., 2009; Perner et al., 2013b) demonstrating its importance for microbial element cycling in some habitats. Sulfurimonas' success has been attributed to its ability to grow chemolithoautotrophically, its metabolic versatility (use of various electron donors, electron acceptors, and inorganic carbon sources), its oxygen tolerance and its environmental sensing systems (Campbell et al., 2006; Sievert et al., 2008b;
Grote et al., 2012; Perner et al., 2013a). We discuss possible horizontal gene transfer events for distinct key genes and link the ability of Sulfurimonas species to operate numerous energy metabolisms under various chemical conditions in different types of environments.

\section{Energy Metabolisms Among Sulfurimonas Species}

\section{Sulfur Metabolism}

The lineage Sulfurimonas combines a group of sulfur-oxidizing bacteria (Inagaki et al., 2003). Many kinds of reduced sulfur compounds, such as sulfide, elemental sulfur, thiosulfate and sulfite, can serve as an electron donor for the growth of Sulfurimonas species, but not all Sulfurimonas species can use all above mentioned sulfur compounds (Table 1). Besides using sulfur compounds for energy generation, they are also essential for biosynthesis, e.g., amino acids like cysteine, and thus need to be assimilated by the cells.

\section{Sulfide:Quinone Reductase}

Except for S. paralvinellae, all strains can oxidize sulfide and produce sulfate as an end product and elemental sulfur and polysulfide as intermediate products. For chemolithotrophic bacteria two sulfide oxidizing pathways exist: in one pathway sulfide:quinone reductase (SQR, EC 1.8.5.4) and in the other pathway flavocytochrome $c$ (FCC, also known as flavocytochrome $c$ sulfide dehydrogenase) catalyzes the reaction (Griesbeck et al., 2000). The released electrons are donated to the electron transport chain either at the level of quinone, if SQR is used, or at the level of cytochrome $c$, if FCC is used (Griesbeck et al., 2000). Since no FCC encoding genes are found in any of the known Sulfurimonas' genomes, sulfide oxidation is likely catalyzed by SQR. According to the structure-based sequence fingerprints, SQR proteins have been classified into six types, SQR Types I - VI (Figure 2, Pham et al., 2008; Marcia et al., 2010). However, several aspects on SQR functioning remain unresolved, including whether all Types of SQR bind quinones in the same way, and whether the different SQRs generate the same intermediates and same sulfur products during sulfide oxidation (Marcia et al., 2010).

Most of the genome sequenced Epsilonproteobacteria have Type II, IV, and VI and none have Type I (see Supplementary Table S1 for details). Interestingly, Sulfurimonas species appear to be the only Epsilonproteobacteria that have Type III (except for Arcobacter sp. AF1581) and Type V, aside from Type II, IV, and VI SQRs. Since Type IV SQR is so conserved among all sequenced Sulfurimonas species, it appears highly likely that it is vital for Sulfurimonas' basic cell maintenance. One well characterized Type IV SQR is CT0117 (Accession No. WP_010931811) from Chlorobium tepidum. It is expressed constitutively but apparently primarily supports growth at sulfide levels between 2 and $4 \mathrm{mM}$ (Chan et al., 2009). C. tepidum also contains a Type VI SQR (CT1087, Accession No. WP_010932765). Its transcript is induced at high sulfide concentrations and it is posited to be important for C. tepidum's growth at sulfide concentrations above 


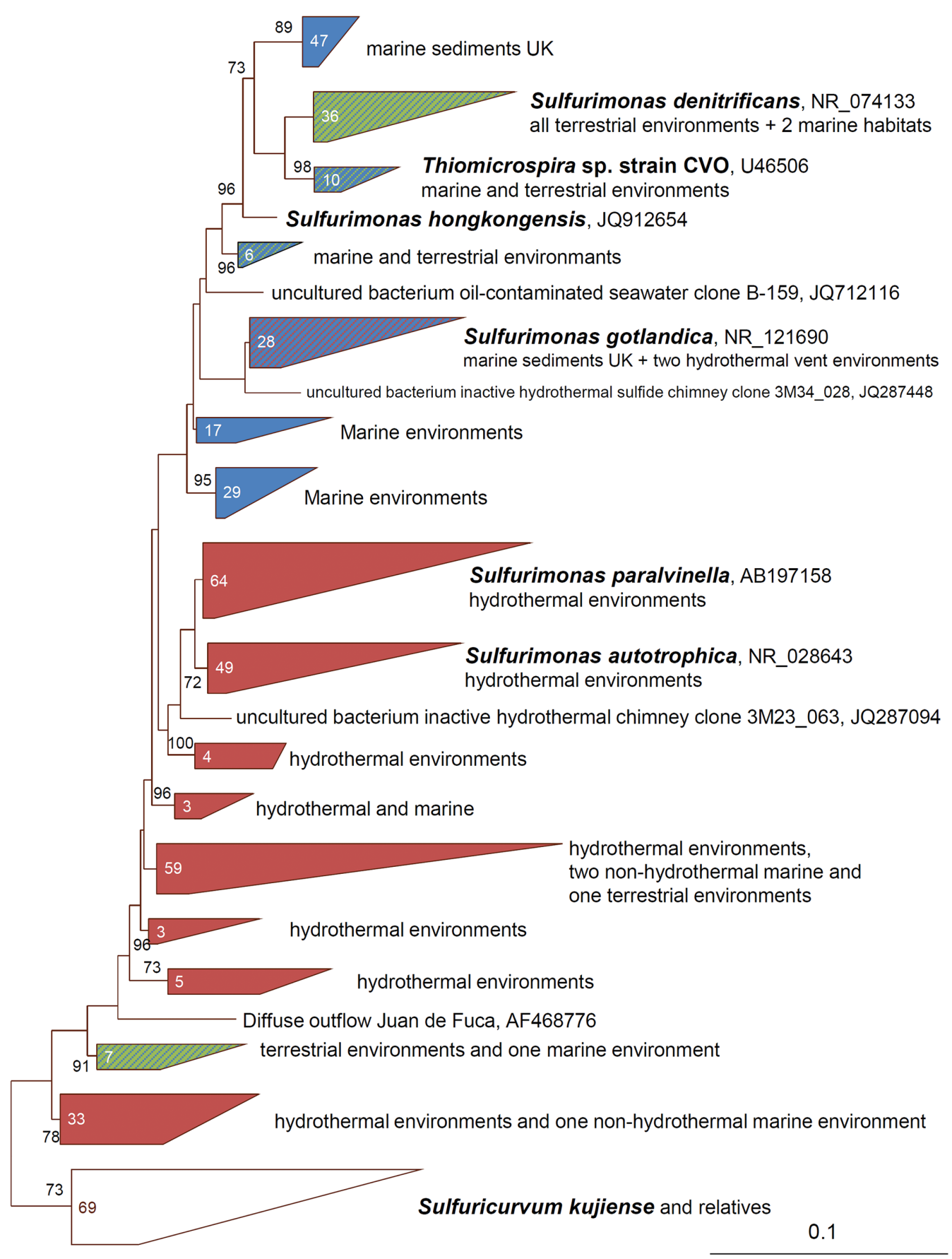

FIGURE 1 | Phylogenetic relationships of 16S rRNA gene sequences of Sulfurimonas species and closest relatives. The 16S rRNA gene sequences were compiled by using the ARB software (www.arb-home.de) (Ludwig et al., 2004) and the alignments manually verified against known secondary structure regions. Maximum-Likelihood based trees with 1000 bootstrap replicates were constructed using PhyML (Guindon and Gascuel, 2003). Phylogenetic trees for 16S rRNA gene sequences were calculated considering only related sequences with lengths of at least 1400 bp. Trees were imported into ARB and shorter sequences were added subsequently to the trees without changing its topology. The number in the clade indicates the amount of sequences identified from the distinct environments. Only Bootstrap values $\geq 70$ are shown. The scale bar represents the expected number of changes per nucleotide position.

$4 \mathrm{mM}$ (Chan et al., 2009). S. denitrificans is the only genome sequenced Sulfurimonas that lacks the Type VI SQR (Figure 2; Supplementary Table S1). Since the Sulfurimonas Type VI SQR phylogeny does not indicate multiple acquisitions from foreign hosts, but suggests that a common ancestor may have had a Type VI SQR, S. denitrificans appears to have lost its version in the course of time. The free sulfide concentration in tidal flats of the Dutch Wadden Sea, where S. denitrificans was originally isolated 
TABLE 1 | List of electron donors, electron acceptors, and carbon sources for Sulfurimonas species.

\begin{tabular}{|c|c|c|c|c|c|c|}
\hline & $\begin{array}{l}\text { Sulfurimonas } \\
\text { denitrificans }\end{array}$ & S. hongkongensis & S. autotrophica & S. paralvinellae & S. gotlandica & $\begin{array}{l}\text { Thiomicrospira } \\
\text { sp. CVO }\end{array}$ \\
\hline \multirow[t]{2}{*}{ Isolated source } & \multicolumn{2}{|c|}{ Coastal marine sediments } & $\begin{array}{l}\text { Deep-sea } \\
\text { hydrothermal } \\
\text { sediments }\end{array}$ & $\begin{array}{l}\text { Nest of } \\
\text { hydrothermal vent } \\
\text { polychaetes }\end{array}$ & $\begin{array}{l}\text { Marine sulfidic water of } \\
\text { a pelagic redox zone }\end{array}$ & Terrestrial oil field \\
\hline & $\begin{array}{l}\text { Dutch Wadden } \\
\text { Sea }\end{array}$ & $\begin{array}{l}\text { Victoria Harbour, } \\
\text { Hong Kong }\end{array}$ & \multicolumn{2}{|c|}{ Mid-Okinawa Trough,Japan } & Central Baltic Sea & $\begin{array}{l}\text { Saskatchewan, } \\
\text { Canada }\end{array}$ \\
\hline \multicolumn{7}{|l|}{ Electron donors } \\
\hline \multicolumn{7}{|c|}{ Reduced inorganic sulfur compounds } \\
\hline Sulfide & + & + & + & - & + & + \\
\hline Element sulfur & + & $N R$ & + & + & + & + \\
\hline Thiosulfate & + & + & + & + & + & - \\
\hline Sulfite & - & NR & - & - & + & NR \\
\hline Hydrogen & + & + & $-^{2}$ & + & + & - \\
\hline \multicolumn{7}{|l|}{ Electron acceptors } \\
\hline Nitrate & + & + & -2 & + & + & + \\
\hline Nitrite & + & - & - & - & + & + \\
\hline Oxygen & + & NR & + & + & $+^{2,3}$ & + \\
\hline \multicolumn{7}{|l|}{ Carbon source } \\
\hline $\begin{array}{l}\text { Carbon } \\
\text { dioxide/Bicarbonate }\end{array}$ & + & + & + & + & + & + \\
\hline Acetate & NR & - & - & - & + & + \\
\hline $\begin{array}{l}\text { Organic } \\
\text { compounds }\end{array}$ & $\begin{array}{l}\text { Formate, fumarate, yeast } \\
\text { extract, alcohol mix as } \\
\text { electron donors }\end{array}$ & - & - & $\begin{array}{l}\text { yeast extract as } \\
\text { sulfur source }\end{array}$ & $\begin{array}{l}\text { Formate, acetate, } \\
\text { yeast extract, } \\
\text { pyruvate, amino } \\
\text { acid mix as electron } \\
\text { donors }\end{array}$ & $\begin{array}{l}\text { Acetate as carbon } \\
\text { source }\end{array}$ \\
\hline Reference & $\begin{array}{l}\text { Timmer-Ten Hoor, 1975; } \\
\text { Timmer-Ten Hoor, 1981; } \\
\text { Labrenz et al., } 2013\end{array}$ & Cai et al., 2014 & Inagaki et al., 2003 & Takai et al., 2006 & $\begin{array}{l}\text { Grote et al., 2012; } \\
\text { Labrenz et al., } 2013\end{array}$ & $\begin{array}{l}\text { Voordouw et al., } \\
\text { 1996; Gevertz } \\
\text { et al., 2000; } \\
\text { Kodama and } \\
\text { Watanabe, } 2003\end{array}$ \\
\hline
\end{tabular}

+, can be used; -, cannot be used; NR, not reported. ${ }^{1}$ Thiomicrospira sp. CVO is reclassified as a Sulfurimonas species in this review. ${ }^{2}$ The properties listed in this

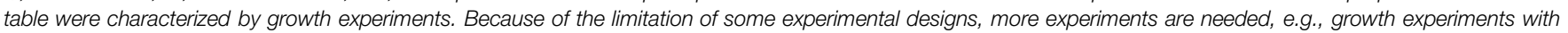

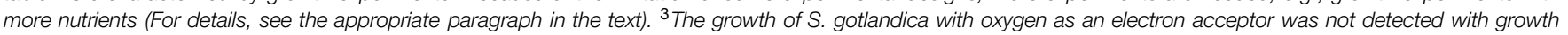

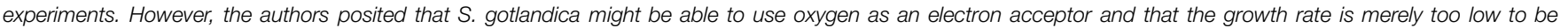
detected with their experimental setup.

from, is much lower than $4 \mathrm{mM}$ (on average $<2.9 \mu \mathrm{M}$ to maximal $21 \mu \mathrm{M}$; at two individual sites maximum sulfide concentrations of $587 \mu \mathrm{M}$ and $1.8 \mathrm{mM}$ were measured; Groenendaal, 1979). Other studies from the German Wadden Sea have yielded similar results (Jansen et al., 2009). Much of the sulfide appears to be buried in form of iron-sulfide (0.16-14 mM; Groenendaal, 1979). Thus, given that in C. tepidum the Type VI SQR is specialized to function at considerably higher sulfide concentrations, i.e., above $4 \mathrm{mM}$, than the Type IV, we hypothesize that $S$. denitrificans does not need a Type VI SQR because it would unlikely encounter free sulfide in the range of what the Type VI SQR from C. tepidum appears to be specialized on. S. denitrificans may also simply deal with elevated sulfide concentrations differently to C. tepidum and thus not need a SQR VI.

No Type I SQR was identified on any of the sequenced Sulfurimonas genomes. However, Type I and Type IV SQRs form a monophyletic clade (Figure 2), where sequences share conserved cysteines required for FAD binding and redox active coupling as well as conserved residues responsible for sulfide access (Pham et al., 2008; Marcia et al., 2009, 2010). This suggests that these two types of SQR may function in the same way and thus it is not surprising that Sulfurimonas species and as such other Epsilonproteobacteria only encode one of these two types.

The Type II SQR appears to have only low (millimolar) affinity to sulfide (cf. Marcia et al., 2010). It is the only SQR that can be found in multiple copies on various epsilonproteobacterial genomes (Figure 2, Supplementary Table S1). Sulfurovum sp. NBC 37-1 even has four copies (Nakagawa et al., 2007). $S$. hongkongensis and S. gotlandica have two copies each, which group together and which, in one case cluster together with the respective SQR from S. denitrificans (Figure 2). In contrast, S. autotrophica's Type II SQR is phylogenetically distinct from the other Sulfurimonas. Distinct roles have been assigned to the Type II SQR: it is involved in sulfur assimilation in the non-pathogenic bacterium Pseudomonas putida KT2440 (Shibata and Kobayashi, 2006), in the heavy metal tolerance in the yeast Saccharomyces pombe (Vande Weghe and Ow, 1999) and in sulfide signaling in mammalian cells (Shahak and Hauska, 


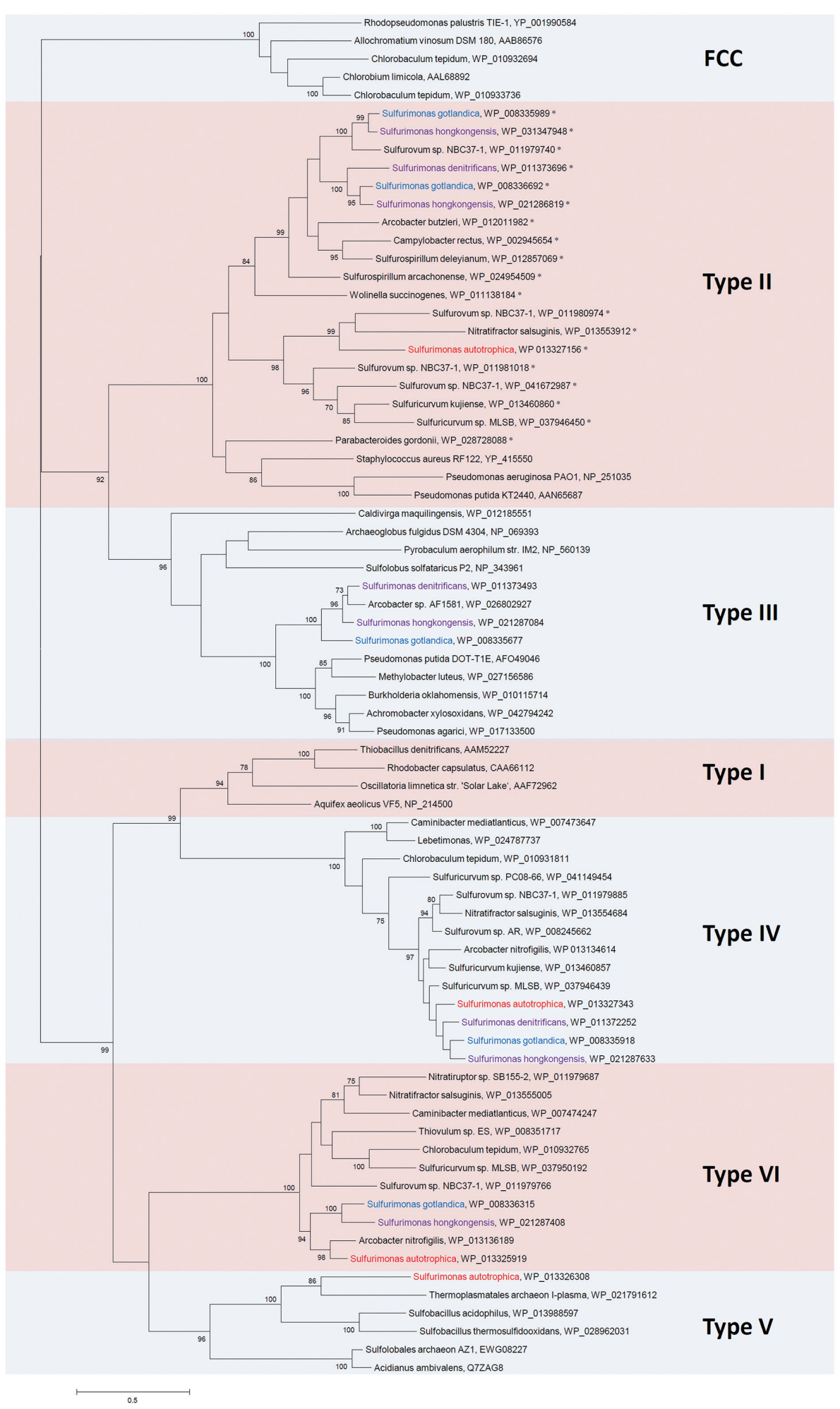

FIGURE 2 | Phylogenetic relationships of SQR sequences to those from Sulfurimonas species. The sequences of SQRs were compared with the non-redundant protein database of NCBI by using BLASTP. The phylogenetic tree was constructed with MEGA6 (Tamura et al., 2013) based on the Maximum-likelihood method with 1000 bootstrap replications after multiple alignments with ClustalW (Larkin et al., 2007). The percentage of bootstrap resamplings $\geq 70$ is indicated on the branches. The scale bar represents the expected number of changes per amino acids position. The types of SQRs are classified according to Marcia et al. (2010). Isolation sources of Sulfurimonas species are indicated in different colors: blue, marine non-vent water system; purple, marine sediments; red, hydrothermal environments. The proteins which has a TAT motif at $\mathrm{N}$-terminus are marked with '*'. 
2008). Given that some Sulfurimonas species can considerably influence the mobility of $\mathrm{Zn}, \mathrm{Cu}$, and $\mathrm{Pb}$ through sulfideoxidizing denitrification in contaminated marine sediments (Shao et al., 2009), some Type II SQRs from Sulfurimonas species may play a role in heavy metal tolerance. Interestingly, all Type II SQRs from Sulfurimonas species and non-Sulfurimonas Epsilonproteobacteria in Supplementary Table S1 have a twoarginine protein translocation (TAT) motif at the $\mathrm{N}$-terminus (indicated in Figure 2). Protein folding in the periplasm may cause problems under specific environmental conditions, such as high salt concentrations (Palmer and Berks, 2012). Under conditions as found at highly reduced and acidic hydrothermal vents, toxic sulfidic environments or heavy metal-contaminated fields protein folding may also be impaired in the periplasm. Hence, in such a case it is useful if the protein can be folded and matured under more controlled conditions in the cytoplasm and then transported to the periplasmic side of the membrane via the translocation pathway (Palmer and Berks, 2012). The TAT motifs in Type II SQRs might be helpful for the translocation of folded and maturated Type II SQRs from the cytoplasm to the periplasmic side in Sulfurimonas and in other Epsilonproteobacteria.

Among the genome sequenced Sulfurimonas species only S. autotrophica contains a Type V SQR (Sikorski et al., 2010b). This $s q r$ lineage is predominated by SQRs from thermoacidophilic bacteria and archaea (Figure 2). While some of these thermoacidophilic microorganisms have been isolated from deep-sea hydrothermal vents (Sulfobacillus acidophilus; Li et al., 2011), the genome sequences of other thermoacidophilic microorganisms with an SQR Type V closely related to that of S. autotrophica (Figure 2), originate from organisms that were isolated from acid mines (Golovacheva and Karavaiko, 1977; Thermoplasmatales archaeon I-plasma, Bioproject: PRJNA209804). These lineages, however, include species that have also been detected in deep-sea hydrothermal vents but for which currently no genome sequences are available (Reysenbach et al., 2006; Henneberger, 2008). S. autotrophica was isolated from a hydrothermal vent and thus is likely the only genome sequenced Sulfurimonas species that directly comes into contact with high abundances of thermoacidophiles. This may explain why it is the only Sulfurimonas we are aware of that appears to have acquired the Type V SQR. However, if acquiring the Type V SQR is of such an advantage, it does not explain why none of the other hydrothermal vent Epsilonproteobacteria carries a Type V SQR on their genome. For example, S. sp. NBC 37-1 has a very similar metabolism to $S$. autotrophica (both are mesophiles that can oxidize various reduced sulfur compounds, can use oxygen as electron acceptor and fix $\mathrm{CO}_{2}$ autotrophically) (Campbell et al., 2006), but $S$. sp. NBC 37-1 lacks a Type V SQR (Nakagawa et al., 2007). However, there is also a metabolic difference between these two species: $S$. sp. NBC-37 can additionally use hydrogen as an electron donor and nitrate as an electron acceptor, whereas S. autotrophica cannot (Inagaki et al., 2003; Nakagawa et al., 2007). Therefore, oxidation of reduced sulfur compounds coupled with oxygen as an electron acceptor is very crucial for S. autotrophica. Compared to Type I SQR from Aquifex aeolicus, the Type V SQR has a different 'capping loop', which guarantees sulfide access to the oxidation site and it is expected that sulfide reaches the active site of the enzyme through a differently structured channel (Marcia et al., 2010). We posit that such a structure in Type V SQR may play an important role for sulfide oxidation to enhance energy generation in S. autotrophica. In the thermoacidophilic archaeon Acidianus ambivalens this type of SQR exhibits the highest activity at $70^{\circ} \mathrm{C}$ and $\mathrm{pH} 6.5$ and only $3 \%$ activity was detected at $25^{\circ} \mathrm{C}$ and $\mathrm{pH} 6.5$ (Brito et al., 2009). This indicates that Type $\mathrm{V}$ may have a tolerance to elevated temperatures. Since S. autotrophica's gene clusters with archaeal sqr genes, it has likely acquired its Type $\mathrm{V} s q r$ gene from a member of the domain archaea through horizontal gene transfer.

S. denitrificans, S. gotlandica, and S. hongkongensis all contain a Type III SQR, which form a monophyletic group together with Arcobacter sp. AF1581 (Figure 2). Although, many Type III SQRs are associated with thermophilic archaea, the SulfurimonasArcobacter clade group together with $\beta$ - and $\gamma$-proteobacterial SQRs (Figure 2). Hence, it is unlikely that these SQRs are specialized to function at elevated temperatures, since several bacteria colonizing moderate temperature regimes have this $\mathrm{SQR}$ as well. The Type III SQRs are phylogenetically clustered with Type II SQRs, indicating that they may have similar functions. However, hardly anything is known about the bacterial Type III SQRs. Although a Type III sqr-gene (CT1025, accession No. NP_661917) has been identified in C. tepidum, no SQR activity was detected in the respective membrane proteins when both Type IV and VI sqr genes (CT0117 and CT1087) were deleted (Chan et al., 2009). Consequently, it can be assumed that under the provided conditions the Type III SQR is not catalyzing sulfide oxidation. It may, however, have a specific function under distinct environmental conditions. Since most Epsilonproteobacteria have one or more copies of Type II SQRs, Type III SQRs might not be crucial for Epsilonproteobacteria, which could explain why Type III SQRs are present in only very few epsilonproteobacterial species.

\section{SOX Enzyme System}

Oxidation of reduced sulfur compounds can also be catalyzed by the Sox pathway, which is a thiosulfate-oxidizing multi-enzyme system and a widespread mechanism within sulfur-oxidizing bacteria (Friedrich et al., 2005). SoxXA, SoxYZ, and SoxB make up the Sox multi-enzyme complex and can oxidize the reduced sulfur compounds stepwise, finally producing sulfate excreted out of cells (Frigaard and Dahl, 2008). In the Sox-mediated pathway SoxB encodes the key enzyme sulfate thiohydrolase. Except for Thiomicrospira sp. CVO, all Sulfurimonas species have been shown to utilize thiosulfate (Table 1). More so, all sequenced Sulfurimonas genomes encode all sox genes (soxXYZAB) required for a fully functional Sox multi-enzyme system. (Sievert et al., 2008b; Sikorski et al., 2010b; Grote et al., 2012). According to the presence of SoxCD, the Sox pathway can be grouped into two different versions: (1) SoxCD acts as a sulfur dehydrogenase, and no sulfur globule is accumulated or (2) sulfur is formed as an intermediate because of lacking SoxCD (Frigaard and Dahl, 2008). The soxCD genes were found on all of the sequenced Sulfurimonas genomes, indicating that these species perform the first Sox pathway with the 
presence of SoxCD as sulfur dehydrogenase, which oxidizes sulfane bound to the cysteine residue of SoxYZ to a sulfite anion. The key enzyme SoxB then catalyzes this sulfite anion to sulfate and releases a sulfate group from SoxYZ (Frigaard and Dahl, 2008). The phylogenetic tree of SoxB showed that the SoxB proteins from Sulfurimonas species are closely related and form a monophyletic group (Supplementary Figure S1A), consistent with previous studies (Hügler et al., 2011), and suggesting that it is an essential part of the Sulfurimonas metabolism. Sox enzyme systems are also found in several other Epsilonproteobacteria inhabiting different environments. They include Sulfurovum, Sulfuricurvum, Nitratiruptor, Acrobacter, and Nitratifractor (see Supplementary Table S1), although no growth of strain Nitratifractor salsuginis on thiosulfate could be shown (Nakagawa et al., 2005c).

\section{Sulfite Dehydrogenase}

Sulfite can be oxidized by the sulfite dehydrogenase (SorAB, EC 1.8.2.1), which is a soluble SOR and contains molybdenum pterin as a cofactor (Kappler and Dahl, 2001). SorAB directly oxidizes sulfite to sulfate with cytochrome $c$ as an electron acceptor. Only few of the Epsilonproteobacteria genera have the SOR enzymes encoded on their genomes: besides Sulfurimonas this includes species of the Sulfurovum and Sulfuricurvum (Supplementary Table S1), which have been isolated from sulfide-rich environments (Nakagawa et al., 2005a; Hubert et al., 2012). S. denitrificans is the only genome sequenced Sulfurimonas species that does not encode for the sor $A B$ homologous genes, which coincides with its inability to grow on sulfite (Supplementary Figure S1B; Table 1, Timmer-Ten Hoor, 1981; Sievert et al., 2008b). Growth experiments showed that sulfite can indeed serve as an electron donor for the growth of S. gotlandica (all growth experiments are summarized in Table 1, Grote et al., 2012; Labrenz et al., 2013). However, no sulfitebased growth could be reported for S. autotrophica (Inagaki et al., 2003), despite SOR activity was detected in its cell extracts (Takai et al., 2005). Likewise, S. paralvinellae's cell extract also exhibited SOR activity, but this species does not appear to use sulfite as an electron donor either (Takai et al., 2005, 2006). This, however, can be explained: unlike other sulfite oxidases (EC 1.8.3.1), pathways depending on SorAB are unable to use oxygen as an electron acceptor (Kappler and Dahl, 2001) and its cofactor molybdenum pterin is labile in the presence of oxygen (Rajagopalan and Johnson, 1992). Since the only electron acceptor that $S$. autotrophica can use is oxygen, it has always been cultivated in the presence of oxygen (Inagaki et al., 2003). Under this condition, however, SorAB from S. autotrophica might not be active because of its oxygen-sensitive cofactor. This is in line with its inability to use sulfite as an electron donor (Table 1). The SOR activities that were measured for S. autotrophica and $S$. paralvinellae may in fact reflect the activity of SoxCD in the cell extracts (Sievert et al., 2008a). It is homologous to SOR and has been demonstrated to act as a periplasmic SOR in the Alphaproteobacterium Paracoccus pantotrophus (Kappler and Dahl, 2001). In summary, we conclude that S. gotlandica expresses an active SOR, S. autotrophica contains an inactive SOR, likely because of its aerobic growth, and sor genes are completely lost in S. denitrificans. Since sulfide concentrations can be very low in the Dutch Wadden Sea sediments (Groenendaal, 1979), reactive and instable sulfite is likely very low as well. $S$. denitrificans may have lost these genes due to very low sulfite concentrations in the Dutch Wadden Sea habitat. Should sulfite accumulate intracellularly, the sox enzyme system could step in for detoxification of sulfite. The ability to use sulfite has not been examined in S. hongkongensis. Yet, given that both SorAs form a monophyletic cluster and appear to be similar in structure (Supplementary Figure S1B) we argue that $S$. hongkongensis may express an active SOR like S. gotlandica.

\section{ATPS and APSR}

Besides the above mentioned sulfur metabolisms, another two sulfur metabolizing pathways for either assimilatory sulfate reduction or dissimilatory sulfide oxidation exist that involve the intermediates adenylylsulfate (APS, also called adenosine- $5^{\prime}$ phosphosulfate) or phosphoadenosine- $5^{\prime}$-phosphosulfate (PAPS) and different types of APS reductase (APSR, EC 1.8.4.8 in assimilatory pathway and EC 1.8.99.2 in dissimilatory pathway) and ATP sulfurylase (ATPS, ATP: sulfate adenylyltransferase, EC 2.7.7.4) enzymes (Neumann et al., 2000; Kappler and Dahl, 2001; Frigaard and Dahl, 2008): in the assimilatory sulfate reduction pathway, sulfate is reduced to APS via the ATPS (two subunits, also called CysDN-type ATPS) and then to sulfite via the assimilatory APSR (one subunit, encoded by $c y s H$ gene). Alternatively, APS can also be phosphorylated to PAPS via the APS kinase (CysC) and then to sulfite via the PAPS reductase (also encoded by cysH gene; Neumann et al., 2000; Frigaard and Dahl, 2008). The sulfite is then reduced to sulfide via the sulfite reductase (encoded by cysI) (Neumann et al., 2000). The homologs of the CysDN-type ATPS were found in S. denitrificans, S. gotlandica, and S. autotrophica (cf. Supplementary Figure S1C) (Sievert et al., 2008b; Sikorski et al., 2010b; Grote et al., 2012) but appear to be missing in S. hongkongensis. The homologs of the CysH-type APSR (or PAPS reductase) and of CysI were found only in S. denitrificans and S. gotlandica (cf. Supplementary Figures S1D,E) (Sievert et al., 2008b; Grote et al., 2012). Additionally, CysC was found in S. gotlandica and S. autotrophica (cf. Supplementary Figure $\mathrm{S} 1 \mathrm{~F})$. Hence, $S$. denitrificans is likely performing assimilatory sulfate reduction without PAPS as an intermediate, which was also proposed by Sievert et al. (2008b); and S. gotlandica is probably able to perform assimilatory sulfate reduction without and with PAPS as an intermediate. In contrast, S. autotrophica and $S$. hongkongensis are missing genes encoding key enzymes of this pathway and are thus likely either taking up the required sulfur molecules directly from the environment or have other means to produce the necessary sulfur compounds. In the dissimilatory sulfide oxidation pathway, sulfite is oxidized through the indirect and AMP-dependent oxidation by the dissimilatory APSR (two subunits, encoded by aprBA) to APS and then to sulfate via the ATPS (one subunit, also called as Sat-type ATPS). Interestingly enough, S. denitrificans, S. gotlandica, S. autotrophica, and S. hongkongensis all have a Sat-type ATPS (cf. Supplementary Figure S1C) (Sievert et al., 
2008b; Sikorski et al., 2010b; Grote et al., 2012; Cai et al., 2014). However, since none of these species have an AprBAtype dissimilatory APSR, it appears highly unlikely that this Sat-type ATPS is involved in dissimilatory sulfide oxidation. Also, respective AprBA activities were not detected in cell extracts from S. autotrophica and S. paralvinellae and in cell suspensions of S. denitrificans (Timmer-Ten Hoor, 1981; Takai et al., 2005). Although S. gotlandica was described to be able to operate a dissimilatory sulfide oxidation pathway with APSR (cf. Grote et al., 2012), sequence analyses show that its APSR (Accession No. WP_008339777) contains only one subunit as it is typically found for the assimilatory sulfate reduction pathway (cf. Supplementary Figure S1D, see also above). The absence of the AprBA-type dissimilatory APSR indicates that $S$. denitrificans does not oxidize sulfite through this indirect pathway and thus ATPS likely only plays a role in assimilatory sulfate reduction (Sievert et al., 2008b). Moreso, despite the Sat-type ATPS being typically associated with dissimilatory sulfide oxidation (Neumann et al., 2000), we posit that this Sat-type ATPS is also involved in assimilatory sulfate reduction as also shown in Fungi and yeast (Foster et al., 1994; Ullrich et al., 2001; Frigaard and Dahl, 2008).

\section{Polysulfide Reductase}

Besides functioning as electron donors, sulfur compounds can also be electron acceptors. Although the solubility of elemental sulfur is quite low, polysulfide is formed by dissolving sulfur flower in an aqueous sulfide solution (Hedderich et al., 1998). One of Sulfurimonas species strain NS25-1, which was isolated from a deep-sea hydrothermal vent, can apparently grow with hydrogen as an electron donor and with elemental sulfur as an electron acceptor (Nakagawa et al., 2005b). However, there is no experimental evidence of sulfur reduction taking place in the cultivation. In another Epsilonproteobacteria, namely Wolinella succinogenes, polysulfide is a possible intermediate of sulfur reduction with hydrogen where electrons are transferred from a hydrogenase to the polysulfide reductase (PSR; Hedderich et al., 1998). A similar mechanism was also proposed in the epsilonproteobacterial Nautilia profundicola, isolated from a hydrothermal vent (Campbell et al., 2009).

All genome sequenced Sulfurimonas species harbor PSRhomologs on their genomes (Supplementary Table S1, Supplementary Figure S1G, Sievert et al., 2008b; Sikorski et al., 2010b; Grote et al., 2012; Cai et al., 2014) and we posit that the reduction of elemental sulfur coupled to hydrogen oxidation may also be prevalent in distinct Sulfurimonas species. Phylogenetic analysis shows that PSR catalytic subunits (PsrA) from non-vent Sulfurimonas species form a monophyletic group and are close to those from Sulfuricurvum species, which are terrestrial strains (Supplementary Figure S1G). The PsrA from the hydrothermal-vent isolate $S$. autotrophica is clustered with that of another vent isolate, i.e., Nitratiruptor sp SB155-2 (Supplementary Figure S1G). Hence, PSRs from the same environment but different epsilonproteobacterial genera appear to be more closely related than those from the same genera but different habitats.

\section{Hydrogen Metabolism}

Most Sulfurimonas species are capable of growing with hydrogen as an energy source: S. denitrificans, S. paralvinellae, S. gotlandica, and S. hongkongensis (Table 1; Takai et al., 2006; Sievert et al., 2008b; Labrenz et al., 2013; Cai et al., 2014; Han and Perner, 2014). S. denitrificans and S. hongkongensis can grow with hydrogen and nitrate (Sievert et al., 2008b; Cai et al., 2014; Han and Perner, 2014). S. paralvinellae uses hydrogen as an electron donor in the presence of reduced sulfur compounds (Takai et al., 2006). Hydrogen utilization was also detected in S. gotlandica when it grew in medium with nitrate and thiosulfate (Labrenz et al., 2013). In contrast, S. autotrophica and Thiomicrospira sp. $\mathrm{CVO}$ have not been shown to grow with hydrogen under aerobic (6\%) and anaerobic conditions, respectively (Table 1; Gevertz et al., 2000; Inagaki et al., 2003; Takai et al., 2006).

Epsilonproteobacteria mostly use the [NiFe]-hydrogenase to catalyze the reaction $\mathrm{H}_{2} \leftrightarrow 2 \mathrm{H}^{+}+2 \mathrm{e}^{-}$(Vignais and Billoud, 2007). The [NiFe]-hydrogenase is a heterodimer with a small subunit containing three iron-sulfur clusters and a large subunit containing the active site. They are classified in four groups, namely Groups I to IV (Vignais and Billoud, 2007). Except for some of the human and animal pathogens and Thiovolum, most Epsilonproteobacteria have a broad array of different [NiFe]hydrogenases affiliated with Group I, II, and IV (Supplementary Table S1; Figure 3). Group I hydrogenases are membranebound hydrogenases performing respiratory hydrogen oxidation linked to the reduction of electron acceptors (Vignais and Billoud, 2007). They are found in all five Sulfurimonas species (Figure 3, Supplementary Table S1 and references therein), indicating that this group of hydrogenases might be essential for growth. The periplasmic Group I [NiFe]-hydrogenase of $S$. denitrificans contributes to hydrogen uptake activity in the membrane fractions of the cell extracts (Han and Perner, 2014). In S. paralvinella hydrogen uptake activity was also detected (Takai et al., 2005). However, for S. gotlandica and $S$. hongkongensis these experiments have not been performed to date. In line with lacking growth on hydrogen, no hydrogen uptake activity was detected in the cell extracts of S. autotrophica (Takai et al., 2005). However, since its genome harbors hydrogenases (Sikorski et al., 2010b), under specific environmental conditions $S$. autotrophica may well be able to express hydrogenases and consume hydrogen. S. hongkongensis and S. gotlandica even have two and three Group I [NiFe]hydrogenases, respectively, which may reflect the enzymes' abilities to function at different hydrogen concentrations, as has been suggested in the Epsilonproteobacteria N. profundicola and S. sp. NBC 37-1 (Nakagawa et al., 2007; Campbell et al., 2009). The Group I Sulfurimonas hydrogenases group into different clusters with phylogenetically diverse Epsilonproteobacteria (Figure 3). This may suggest multiple acquisitions or possibly repeated loss of these hydrogenases among the Sulfurimonas species.

Group II hydrogenases were not found in the hydrothermal deep-sea vent Sulfurimonas species, but were present in the isolates from marine water and sediments, i.e., S. denitrificans, S. hongkongensis and S. gotlandica (Figure 3). In these habitats hydrogen is less abundant than in hydrothermal vents, suggesting 


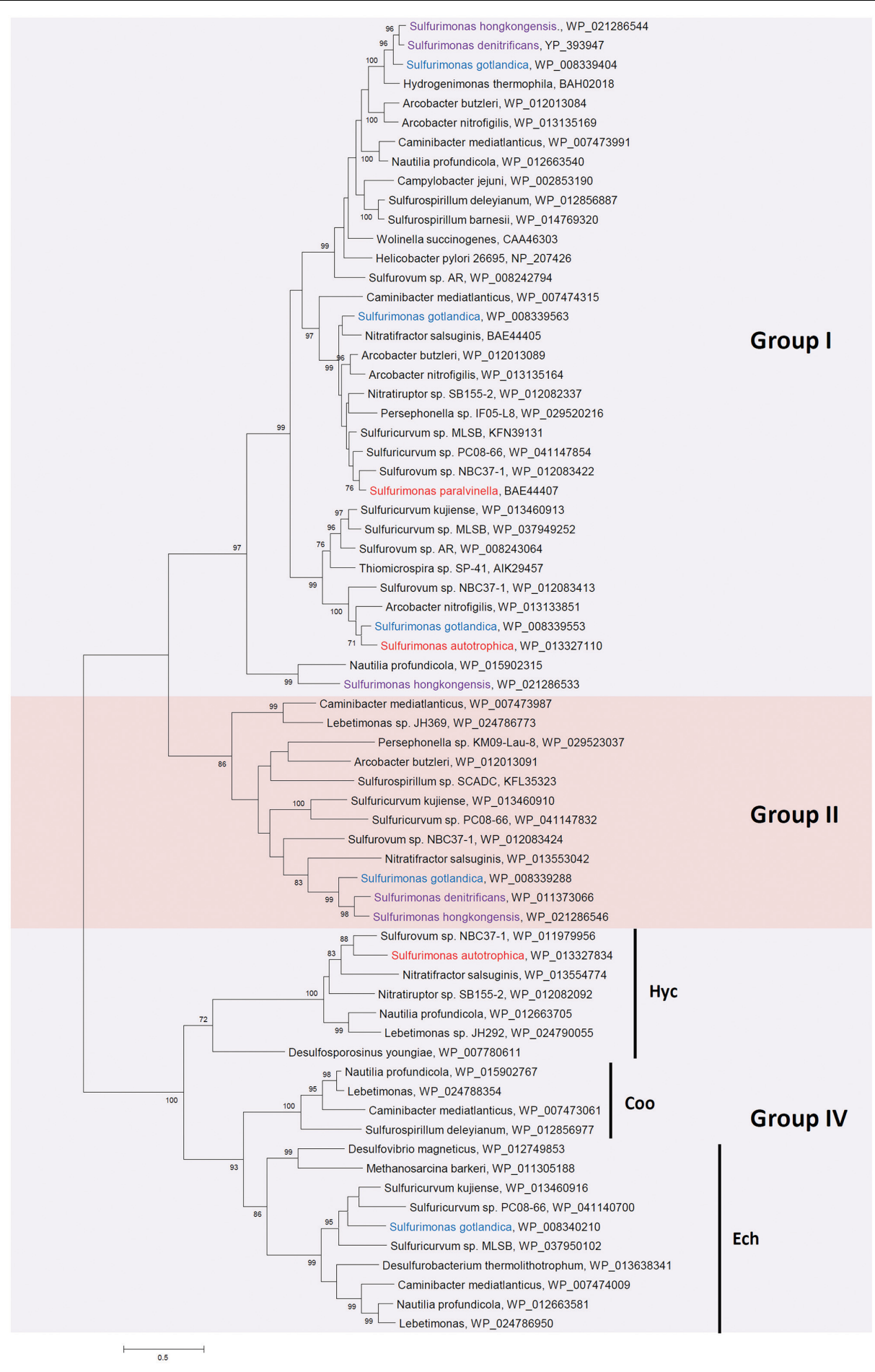

FIGURE 3 | Phylogenetic relationships of hydrogenase large subunit sequences to those from Sulfurimonas species. The phylogenetic tree was constructed with the same method as described in Figure 2. The percentage of bootstrap resamplings $\geq 70$ is indicated on the branches. The scale bar represents the expected number of changes per amino acids position. The groups of hydrogenases are classified according to Vignais and Billoud (2007). Isolation sources of Sulfurimonas species are indicated in different colors: blue, marine non-vent water system; purple, marine sediments; red, hydrothermal environments.

that this group of hydrogenases may be important under low hydrogen concentrations. Intriguingly, no hydrogen uptake activity in the soluble protein fractions of $S$. denitrificans was detected, even though the transcripts of the large subunit of the cytoplasmic Group II [NiFe]-hydrogenase was recovered by reverse transcription PCR (Han and Perner, 2014). Its 
role thus remains speculative: in other Epsilonproteobacteria it has been proposed to function as a hydrogen-sensing hydrogenase (Nakagawa et al., 2007). In contrast, Sievert et al. (2008b) posited that the cytoplasmic hydrogenase of S. denitrificans most likely functions as a catalytically active hydrogenase because of the sequence similarity of both subunits to the enzyme from $A$. aeolicus, where it is involved in the reverse electron transport whereby increasing efficiency of growth (Brugna-Guiral et al., 2003). Alternatively, it has been suggested that the Group II hydrogenase is important during phases of hydrogen and polysulfide starvation, where internal carbon storages are used up due to running the oxidative tricarboxylic acid cycle (Campbell et al., 2009). Reduced ferredoxin could be reoxidized by the hydrogenase whereby the cycle could continue and hydrogen could be produced favorably (Campbell et al., 2009). Further experiments will be necessary to confirm the actual role of the cytoplasmic hydrogenase for $S$. denitrificans and the other Sulfurimonas species that encode one.

Sulfurimonas differ from several other hydrogen metabolizing Epsilonproteobacteria in that they have very few Group IV hydrogenases (Supplementary Table S1), which are hydrogenevolving, energy-conserving, membrane-associated multimeric enzymes (Vignais and Billoud, 2007). S. autotrophica and S. gotlandica have one Group IV [NiFe]-hydrogenase each, Hyc and Ech, respectively (Figure 3; Supplementary Table S1) (Sikorski et al., 2010b; Grote et al., 2012). Hyc from S. autotrophica is clustered with Hycs from other Epsilonproteobacteria, which are all isolated from hydrothermal deep-sea vents (Figure 3; Supplementary Table S1). Since hydrothermal vents are extremely acidic ( $\mathrm{pH} 2-4)$ (Fisher et al., 2007), Hyc from vent isolates might be related to anaerobic acid resistance through proton conversion as proposed in anaerobic growing cultures of Escherichia coli (Noguchi et al., 2010). Here, Hyc catalyzes hydrogen generation with protons at low external $\mathrm{pH}$ (Noguchi et al., 2010). Another Group IV hydrogenase, Ech, has been well characterized in the archaeon Methanosarcina barkeri. It catalyzes hydrogen formation through reduced ferredoxin and plays a role in carbon fixation from $\mathrm{CO}_{2}$ and acetate (Meuer et al., 2002). Likewise, it may function in the same way in S. gotlandica.

\section{Nitrogen Metabolism}

S. denitrificans was the first isolated Sulfurimonas species and was characterized as a denitrifier using thiosulfate as an electron donor and nitrate as an electron acceptor (Timmer-Ten Hoor, 1975). Numerous 16 S rRNA gene sequences have been identified since from coastal marine sediments and the Baltic Sea that are closely related to $S$. denitrificans and appear to account for much of the autotrophic denitrification (Brettar et al., 2006; Shao et al., 2009; Zhang et al., 2009). This indicates that $S$. denitrificans-based denitrification plays an important role in nitrogen and carbon cycling in these and likely similar environments. Except for S. autotrophica, all strains including Thiomicrospira sp. CVO are known to grow with nitrate as an electron acceptor (Timmer-Ten Hoor, 1981; Voordouw et al., 1996; Inagaki et al., 2003; Takai et al., 2006; Grote et al., 2012;
Cai et al., 2014). However, nitrate turnover in the distinct Sulfurimonas differs considerably: S. denitrificans uses nitrate up rapidly, namely $20 \mathrm{mM}$ nitrate in three (with hydrogen) to six (without hydrogen) days during growth when coupled to thiosulfate-oxidation (Han and Perner, 2014). S. gotlandica uses roughly $1 \mathrm{mM}$ nitrate within 9 days in the presence of thiosulfate (Mammitzsch et al., 2014) and S. paralvinellae utilizes $\sim 10 \mathrm{mM}$ nitrate within $90 \mathrm{~h}$ in the presence of hydrogen and sulfur (Takai et al., 2006). S. denitrificans, S. gotlandica, and Thiomicrospira sp. CVO can additionally grow with nitrite as an electron acceptor (see Table 1 for references). All genes required for the complete reduction of nitrate to nitrogen gas, i.e., nitrate reductases, nitrite reductases, nitric oxide reductases and nitrous oxide reductases, were found on the genomes of S. denitrificans, S. hongkongensis, S. autotrophica, and S. gotlandica (Sievert et al., 2008b; Sikorski et al., 2010b; Grote et al., 2012; Cai et al., 2014). However, even though the genome of S. autotrophica contains the napAGHBFLD operon (Sikorski et al., 2010b), $S$. autotrophica is incapable of growing at a concentration of $5 \mathrm{mM}$ sodium nitrate under the tested conditions (Inagaki et al., 2003).

All so far isolated and tested Sulfurimonas species have the periplasmic nitrate reductase (Nap) catalytic subunit (NapA) (Figure 4) and all so far genome sequenced Sulfurimonas species have the napAGHBFLD operon (Sievert et al., 2008b; Sikorski et al., 2010b; Grote et al., 2012; Cai et al., 2014). This organization of the nap operon is distinct from other proteobacterial nap operons (Potter et al., 2001), but is conserved in deep-sea hydrothermal vent Epsilonproteobacteria (Vetriani et al., 2014). Since such vent NapAs have a high affinity for nitrate, they may represent the adaption of Sulfurimonas species to the low nitrate concentrations in vent systems (Vetriani et al., 2014) and other nitrate low environments.

Interestingly, epsilonproteobacterial NapAs of isolates from hydrothermal vents clustered, while those from non-vent but marine habitats grouped and were closely related to Arcobacter species (Figure 4). Thus, the NapA proteins from the same habitats appear to be more similar to each other than to those from the same genus.

\section{Oxygen Reduction}

Besides nitrate and nitrite, oxygen can also serve as an electron acceptor in most Sulfurimonas species and Thiomicrospira sp. CVO (Table 1). All four sequenced genomes of Sulfurimonas species contain a ccoNOQP operon (also called fixNOQP) encoding a $c b b_{3}$-type cytochrome $c$ oxidase $\left(c b b_{3}\right.$-COX) (Table 2, Sievert et al., 2008b; Sikorski et al., 2010b; Grote et al., 2012; Cai et al., 2014), which is a proton-pumping respiratory heme-copper oxidase involved in transferring electrons from cytochrome $c$ to oxygen and reduction of oxygen to water (Pitcher and Watmough, 2004). Because of its high affinity for oxygen, it plays an important role in supporting bacterial growth under microaerobic conditions (Marchal et al., 1998; Bertini et al., 2005). Phylogenetic analysis of the $c b b_{3}-\mathrm{COX}$ catalytic subunit (CcoN/FixN) shows that these subunits from 


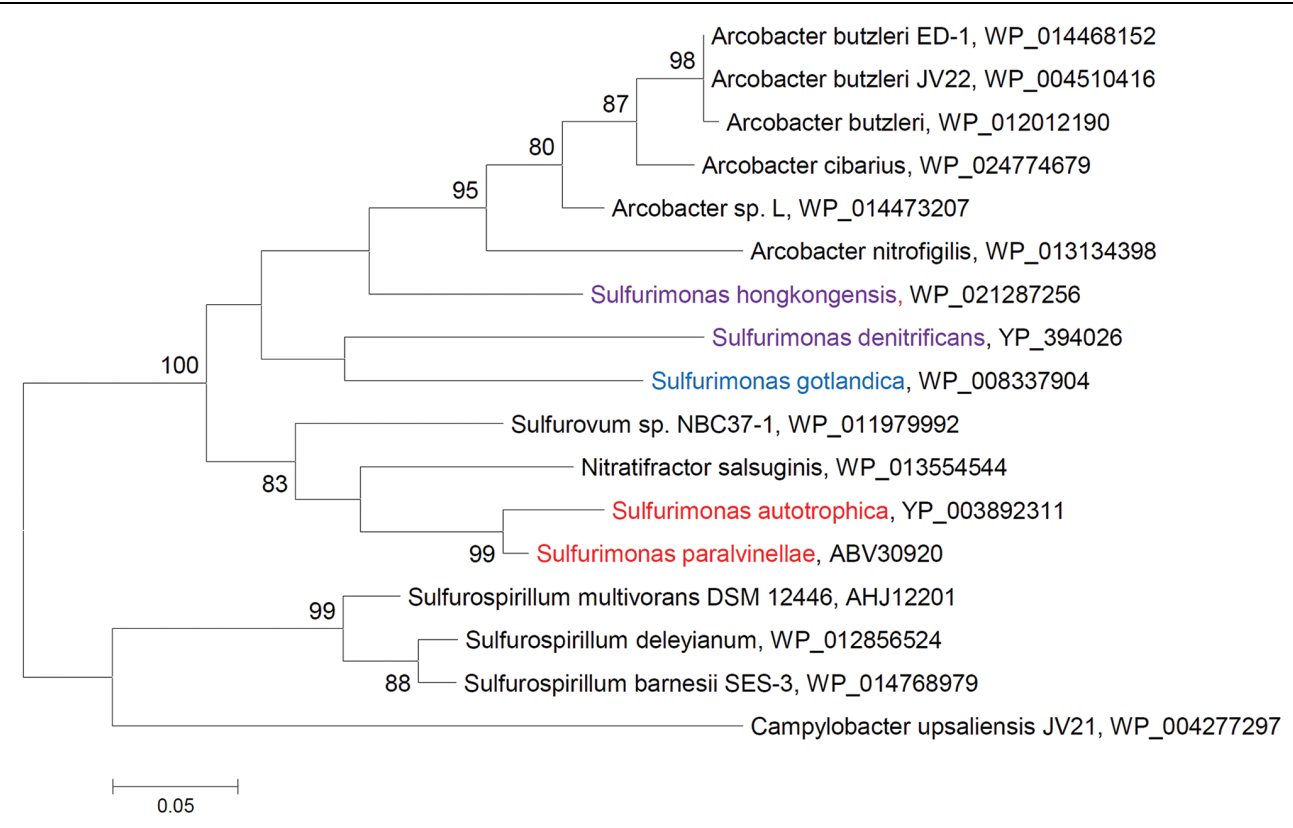

FIGURE 4 | Phylogenetic relationships of NapA sequences to those from Sulfurimonas species. The phylogenetic tree was constructed with the same method as described in Figure 2. The percentage of bootstrap resamplings $\geq 70$ is indicated on the branches. The scale bar represents the expected number of changes per amino acids position. Isolation sources of Sulfurimonas species are indicated in different colors: blue, marine non-vent water system; purple, marine sediments; red, hydrothermal environments.

Sulfurimonas species form a monophyletic cluster (Clade I in Supplementary Figure $\mathrm{S} 1 \mathrm{H}$ ), indicating that this type of $c b b_{3}$ COXs is important for oxygen reduction in Sulfurimonas species. These type Sulfurimonas' $c b b_{3}$-COXs are clustered within CcoNs from non-Sulfurimonas Epsilonproteobacteria, which can also use oxygen as electron acceptors (Clade I in Supplementary Figure $\mathrm{S} 1 \mathrm{H}$ ), indicating that these $c b b_{3}$-COXs are conserved enzymes throughout the group. Among Epsilonproteobacteria only $S$. denitrificans, S. autotrophica, and S. sp. NBC 371 contain an additional $\mathrm{CcoN}$, which is located on different parts of the genome than the ccoNOQP operon (Nakagawa et al., 2007; Sievert et al., 2008b; Sikorski et al., 2010b). These second Sulfurimonas' CcoNs are clustered with those from Aquificales and Actinobacteria (Clade II in Supplementary Figure $\mathrm{S} 1 \mathrm{H}$ ). The oxygen reductase activity of this type CcoN was demonstrated in Aquificales: Sulfurihydrogenibium azorense (Ducluzeau et al., 2008). The growth experiments illustrated that $S$. denitrificans and $S$. autotrophica can indeed use oxygen as an electron acceptor (Timmer-Ten Hoor, 1981; Inagaki et al., 2003), coinciding with the presence of a ccoNOQP operon on their genomes. In contrast, no growth of $S$. gotlandica with oxygen as a sole electron acceptor was detected, despite the ccoNOQP operon's presence on its genome (Grote et al., 2012; Labrenz et al., 2013). Nevertheless, the authors claimed that S. gotlandica might be able to use oxygen as an electron acceptor but that the growth rate is too low for detection with their experimental design. In the presence of oxygen, $S$. gotlandica can still grow using nitrate as an electron acceptor. When the oxygen concentration is below $10 \%, S$. gotlandica's growth is not affected in the medium (with nitrate and thiosulfate), but growth is considerably impaired when the oxygen concentration exceeds 20\% (Labrenz et al., 2013). This phenomenon can be explained by the induction of $c c o N$ expression with low oxygen tension (Preisig et al., 1993; Mouncey and Kaplan, 1998) and its possible function as an oxygen scavenger to protect oxygen sensitive enzymes (Sievert et al., 2008b). Under low oxygen conditions, the expression of $c c o N$ is induced and the activity of $c b b_{3}-\mathrm{COX}$ is higher than under high oxygen conditions, diminishing the amount of oxygen and thereby protecting the oxygen-labile enzymes. Growth of S. gotlandica with nitrate and thiosulfate can then proceed. In contrast, under high oxygen concentrations the activity of $c b b_{3}$-COX is lower, the activities of oxygen-sensitive enzymes for the growth with nitrate and thiosulfate are reduced, resulting in less growth. S. hongkongensis was defined as a strict anaerobe (Cai et al., 2014) and there is no more information about its usage of oxygen. However, apparently $S$. hongkongensis survived after being exposed to air at $4^{\circ} \mathrm{C}$ for up to 8 weeks (personal communication with $\mathrm{M}$. Shao and T. Zhang), which does suggest some oxygen tolerance. Nevertheless, since it has the same type of ccoNOQP operon and it lacks the same additional $c c o N$ gene as $S$. gotlandica, we expect it to behave in a similar way to oxygen as $S$. gotlandica does.

\section{Autotrophic Carbon Dioxide Fixation}

Growth experiments revealed that Sulfurimonas species fix carbon dioxide autotrophically via the reductive tricarboxylic acid (rTCA) cycle. This is supported through genetic and enzymatic studies (Hügler et al., 2005; Takai et al., 2005; Sievert et al., 2008b; Grote et al., 2012; Cai et al., 2014). Genes encoding 
TABLE 2 | List of key enzymes for sulfur, nitrogen, hydrogen, and carbon metabolisms in Sulfurimonas species.

\begin{tabular}{|c|c|c|c|c|c|c|}
\hline & S. denitrificans & S. hongkongensis & S. autotrophica & S. paralvinellae & S. gotlandica & $\begin{array}{l}\text { Phylogenic tree } \\
\text { of catalytic } \\
\text { subunits }\end{array}$ \\
\hline Genome size & $2.20 \mathrm{Mbp}$ & $2.30 \mathrm{Mbp}$ & $2.15 \mathrm{Mbp}$ & NR & $2.95 \mathrm{Mbp}$ & \\
\hline \multicolumn{7}{|l|}{ Sulfur metabolisms } \\
\hline $\begin{array}{l}\text { Sulfide:quinone } \\
\text { reductase } \\
(\mathrm{SQR})\end{array}$ & $+(3)$ & $+(5)$ & $+(4)$ & NR & $+(5)$ & Figure 2 \\
\hline $\begin{array}{l}\text { Sulfur oxidation protein } \\
\text { (Sox) }\end{array}$ & + & + & + & NR & + & $\begin{array}{l}\text { Supplementary } \\
\text { Figure S1A }\end{array}$ \\
\hline $\begin{array}{l}\text { Sulfite dehydrogenase } \\
\text { (SOR) }\end{array}$ & - & + & + & NR & + & $\begin{array}{l}\text { Supplementary } \\
\text { Figure S1B }\end{array}$ \\
\hline $\begin{array}{l}\text { adenylylsulfate reductase } \\
\text { (APSR) }\end{array}$ & - & - & - & $N R$ & - & \\
\hline $\begin{array}{l}\text { ATP sulfurylase } \\
\text { (ATPS, ATP:sulfate } \\
\text { adenylyltransferase) }\end{array}$ & $+(2)$ & + & $+(2)$ & NR & $+(3)$ & $\begin{array}{l}\text { Supplementary } \\
\text { Figure S1C }\end{array}$ \\
\hline \multicolumn{7}{|l|}{ Nitrogen metabolisms } \\
\hline $\begin{array}{l}\text { Periplasmic nitrate } \\
\text { reductase (Nap) }\end{array}$ & + & + & + & + & + & Figure 4 \\
\hline $\begin{array}{l}\text { Cytoplasmic nitrate } \\
\text { reductase (Nas) }\end{array}$ & - & - & + & NR & + & \\
\hline \multicolumn{7}{|l|}{ Hydrogen metabolism } \\
\hline Hydrogenase & $+(2)$ & $+(3)$ & $+(2)$ & + & $+(5)$ & Figure 3 \\
\hline \multicolumn{7}{|l|}{ Carbon metabolisms } \\
\hline $\begin{array}{l}\text { Oxoglutarate:ferredoxin } \\
\text { oxidoreductase (OOR) }\end{array}$ & + & + & + & + & + & \\
\hline $\begin{array}{l}\text { Pyruvate:ferredoxin } \\
\text { oxidoreductase (POR) }\end{array}$ & + & + & + & NR & + & \\
\hline $\begin{array}{l}\text { ATP-dependent citrate } \\
\text { lyase }(\mathrm{ACL})\end{array}$ & + & + & + & + & + & $\begin{array}{l}\text { Supplementary } \\
\text { Figure S1I }\end{array}$ \\
\hline \multicolumn{7}{|l|}{ Oxygen reduction } \\
\hline $\begin{array}{l}c b b_{3} \text {-type cytochrome c } \\
\text { oxidase (COX) }\end{array}$ & $+(2)$ & + & $+(2)$ & NR & + & $\begin{array}{l}\text { Supplementary } \\
\text { Figure } \mathrm{S} 1 \mathrm{H}\end{array}$ \\
\hline Reference & Sievert et al., 2008b & Cai et al., 2014 & Sikorski et al., 2010b & $\begin{array}{l}\text { Takai et al., 2005; } \\
\text { Vetriani et al., } 2014\end{array}$ & Grote et al., 2012 & \\
\hline
\end{tabular}

+, present; the number of enzymes are listed in the brackets; -, not present; NR, not reported. *, Thiomicrospira sp. CVO is not listed in this table, because its genome sequence is not available and none of the genes have been PCR-amplified.

key enzymes, e.g., 2-oxoglutarate:ferredoxin oxidoreductase (OOR), pyruvate:ferredoxin oxidoreductase (POR), and ATPdependent citrate lyase (ACL), for the reductive citric acid cycle are found on the genomes of $S$. denitrificans, S. autotrophica, S. gotlandica, and S. paralvinellae either by genome sequencing or PCR amplification (Supplementary Figure S1I; Table 2, Takai et al., 2005; Sievert et al., 2008b; Sikorski et al., 2010b; Grote et al., 2012). The activities of OORs, PORs, and ACLs were detected in the cell extracts of S. denitrificans (Hügler et al., 2005), S. autotrophica and S. paralvinellae (Takai et al., 2005). It is known that the rTCA cycle genes are very abundant in the sequences from deep-sea hydrothermal vents (Campbell and Cary, 2004). Phylogenetic analysis shows that AclBs from Sulfurimonas species form a monophyletic group (Supplementary Figure S1I), suggesting this pathway might be conserved in Sulfurimonas species. AclBs from hydrothermal vent isolates $S$. autotrophica and $S$. paralvinellae are clustered together and AclBs from non-vent-isolated Sulfurimonas species are clustered together, indicating that different environments influence the evolution of AclB proteins.

\section{Usage of Organic Compounds}

Although Sulfurimonas species are characterized as chemolithoautotrophs, some organic compounds were found to contribute to their growth (Table 1). For example, $S$. paralvinellae can use yeast extract besides reduced sulfur species as sulfur source (Takai et al., 2006). Thiomicrospira sp. CVO and S. gotlandica can use acetate in addition to carbon dioxide and bicarbonate as a carbon source (Table 1, Gevertz et al., 2000; Kodama and Watanabe, 2003; Labrenz et al., 2013). Aside from inorganic compounds, S. denitrificans can grow with formate, fumarate, yeast extract, alcohol mix as electron donors and $S$. gotlandica can grow with formate, acetate, yeast extract, pyruvate, and amino acid mix as electron donors (Labrenz et al., 2013). The ability of Sulfurimonas species to additionally exploit organic 
compounds suggests that those versatile metabolic strategies max contribute to the successful colonization of a broad type of environments.

\section{Structural Genes of Key Energy Metabolisms and Horizontal Gene Transfer}

Of the investigated structural proteins from Sulfurimonas species the SoxBs, CcoNs (Clade I) and AclBs form monophyletic groups within the Epsilonproteobacteria (Figure 2; Supplementary Figures S1A,H,I) suggesting that these genes are vital for the cells' survival and likely originate from a common ancestor. However, other genes of key pathways are phylogenetically positioned with non-Sulfurimonas Epsilonproteobacteria or non-Epsilonproteobacteria: e.g., Type III and Type V SQRs are clustered with SQRs from mesophilic bacteria (including a group of pathogens), thermophilic bacteria (e.g., Sulfobacillus) and thermophilic or/and acidophilic archaea, e.g., Archaeoglobus, Pyrobaculum, and some Sulfolobales and Thermoplasmatales (Figure 2); and CcoNs (Clade II) from two Sulfurimonas species cluster with CcoNs from the hydrothermal vent isolates S. sp. NB C37-1, Aquificales and Actinobacteria (Supplementary Figure $\mathrm{S} 1 \mathrm{H}$ ). The distribution of the structural protein NapAs and PsrAs from Sulfurimonas species is somehow different: NapAs from the hydrothermal vent isolated Sulfurimonas species and the ones from nonvent isolates form a clade each (Figure 4). NapA proteins from the two hydrothermal vent isolates $S$. paralvinellae and S. autotrophica are clustered with other deep-sea vent Epsilonproteobacteria (e.g., Sulfurovum and Nitratifractor) and NapA proteins from Sulfurimonas species isolated from marine non-vent sediments and the water column are clustered with pathogenic Epsilonproteobacteria Arcobacter species (Figure 4). Hence, NapA proteins from the hydrothermal vent organisms Sulfurovum, Nitratifractor, and Sulfurimonas are more similar to each other than NapAs from other marine Sulfurimonas species. The same pattern is also observed for PsrA proteins (Supplementary Figure S1G). In summary, these phylogenies strongly indicate the large role that horizontal gene acquisitions (from archaea, Aquificales, Actinobacteria, Gammaproteobacteria, and other Epsilonproteobacteria) appear to have had for shaping Sulfurimonas' genomes and physiological properties in successfully surviving and flourishing in chemically distinct environments. This conclusion is consistent with the finding that besides conserved core genes, Epsilonproteobacteria generally also contain niche-specific genes, which are important to their metabolic diversity and versatility (Zhang and Sievert, 2014).

\section{Global Distributions and Metabolisms}

Epsilonproteobacteria can colonize a broad range of habitats ranging from animal and human bodies, to terrestrial and marine environments, which include shallow waters and sediments but also deep sea hydrothermal vents (cf. Supplementary Table S1 and references therein). However, in the chemically distinct types of habitats that are inhabited by members of this lineage, the genomic inventory can differ considerably: particularly among the genes encoding SoxB (thiosulfate oxidation), SorA (sulfite oxidation), SQR (sulfide oxidation) and hydrogenases (both hydrogen uptake and evolution) (see Supplementary Table S1). Noticeably, the genomes of strains like the heterotrophic Helicobacter, Campylobacter, and Wolinella, which are limited to one type of habitat, namely animals and humans, appear relatively depleted in certain energy metabolisms. Nakagawa et al. (2007) have recently suggested that members of these groups lost hydrogen sensing and evolving hydrogenases as well as the ability to fix $\mathrm{CO}_{2}$ autotrophically because they have adapted themselves to their lifestyle, in case of Helicobacter and Campylobacter a pathogenic lifestyle, and do not depend on a diverse suit of metabolisms any longer.

Besides these heterotrophs colonizing only a comparable narrow habitat range, other epsilonproteobacterial heterotrophs exist, which have a broader global distribution: heterotrophic Arcobacter and Sulfurospirillum have been isolated from globally widespread and chemically diverging biotopes including terrestrial and marine provinces (Supplementary Table S1). While the Arcobacter and Sulfurospirillum listed in Supplementary Table S1 were isolated from humans, marshland, freshwater marsh and mud, forest ponds (McClung et al., 1983; Stolz et al., 1999; Miller et al., 2007; Sikorski et al., 2010a), their genomes still appear relatively limited with respect to key enzymes of different sulfur metabolizing pathways. This is likely related to the environments they were isolated from, either rich in organic compounds or rich in elemental sulfur. For example, some Arcobacter species were isolated from organic rich crude-oil contaminated sea water, petroleum reservoir, animals and plants (Kiehlbauch et al., 1991; Snaidr et al., 1997; Frias-Lopez et al., 2002; Grabowski et al., 2005; Prabagaran et al., 2007). Therefore, they are adapted to using different organic compounds from their habitats as energy sources (e.g., dimethyl sulfoxide as electron acceptor) and carbon sources (e.g., organic and amino acids) (Miller et al., 2007). It will be interesting to sequence the genome of the only so far isolated autotrophic Arcobacter (Wirsen et al., 2002) and compare the genetic inventory with that from the heterotrophic Arcobacter. Sulfurospirillum deleyianum was isolated from an anaerobic enrichment culture targeting Desulfuromonas where a medium that was rich in elemental sulfur was used (Wolfe and Penning, 1977). Thus, in the latter case, sulfur reduction appears to be more important for growth than oxidation of reduced sulfur compounds. In contrast, these genera can harbor a relatively broad suit of hydrogenases (Supplementary Table S1), which may catalyze hydrogen oxidation coupled to the reduction of various electron acceptors, including nitrate, oxygen, elemental sulfur, and organic compounds, e.g., fumarate (McClung et al., 1983; Stolz et al., 1999; Miller et al., 2007). Likewise, the anaerobic hydrogen oxidizers, which have so far only been isolated from hydrothermal vents, namely Caminibacter, Nautilia, and Lebetimonas, exhibit an exceptional high number of distinct hydrogenases (Supplementary Table S1). However, they appear to 
be relatively limited in their inventory for key enzymes of sulfur oxidizing metabolisms, which coincides with their physiology (Voordeckers et al., 2005; Smith et al., 2008; Campbell et al., 2009; Giovannelli et al., 2011; Meyer and Huber, 2014).

The broadest suit of genes encoding for enzymes capable of oxidizing thiosulfate, sulfite and sulfide as well as hydrogen uptake and evolution can be found among autotrophic, aerobic sulfur oxidizing species, primarily among Sulfurimonas, Sulfurovum, and Sulfuricurvum (Nakagawa et al., 2007; Sievert et al., 2008b; Sikorski et al., 2010b; Grote et al., 2012; Han et al., 2012; Park et al., 2012; Cai et al., 2014; Hamilton et al., 2014; Tan and Foght, 2014). Sulfurimonas, Sulfuricurvum, and Sulfurovum have been isolated from marine sediments and hydrothermal vents, whereas Sulfurimonas and Sulfuricurvum have additionally been found in terrestrial systems (NCBI database, Timmer-Ten Hoor, 1975; Voordouw et al., 1996; Inagaki et al., 2003; Kodama and Watanabe, 2004; Takai et al., 2006; Nakagawa et al., 2007; Park et al., 2012; Labrenz et al., 2013; Cai et al., 2014; Hamilton et al., 2014; Tan and Foght, 2014). In these type of habitats, sulfide concentrations range from being undetectable up to several milimolar (Groenendaal, 1979; Brettar and Rheinheimer, 1992; Gevertz et al., 2000; Nakagawa et al., 2005a). All these three genera have Type IV and VI SQRs (Supplementary Table S1), likely to cope with different concentrations of sulfide, such as free sulfide in hydrothermal vents and metal sulfide in marine sediments or contaminated landmasses. Additionally, they have one or more copies of Type II SQRs (Supplementary Table S1), which may compensate for the function of other SQRs under environmental conditions, where folding of SQRs in the periplasm is becoming increasingly difficult and thus no functional SQR enzyme would otherwise be available. In case of Sulfurimonas, some species harbor Type III and V SQRs besides Type II, IV, and VI SQRs (Supplementary Table S1), which may either enhance the energy generation with sulfide or have different functions, such as detoxification and sulfide signaling. With respect to hydrogen metabolism,

\section{References}

Akerman, N. H., Butterfield, D. A., and Huber, J. A. (2013). Phylogenetic diversity and functional gene patterns of sulfur-oxidizing subseafloor Epsilonproteobacteria in diffuse hydrothermal vent fluids. Front. Microbiol. 4:185. doi: $10.3389 /$ fmicb.2013.00185

Bertini, I., Cavallaro, G., and Rosato, A. (2005). Cytochrome $c$ : occurrence and functions. Chem. Rev. 106, 90-115. doi: 10.1021/cr050241v

Brettar, I., Labrenz, M., Flavier, S., Bötel, J., Kuosa, H., Christen, R., et al. (2006). Identification of a Thiomicrospira denitrificans-like Epsilonproteobacterium as a catalyst for autotrophic denitrification in the central Baltic Sea. Appl. Environ. Microbiol. 72, 1364-1372. doi: 10.1128/AEM.72.2.1364-137 2.2006

Brettar, I., and Rheinheimer, G. (1992). Influence of carbon availability on denitrification in the central Baltic Sea. Limnol. Oceanogr. 37, 1146-1163. doi: 10.4319/lo.1992.37.6.1146

Brito, J. A., Sousa, F. L., Stelter, M., Bandeiras, T. M., Vonrhein, C., Teixeira, M., et al. (2009). Structural and functional insights into sulfide:quinone oxidoreductase. Biochemistry 48, 5613-5622. doi: 10.1021/bi9 003827

Brugna-Guiral, M., Tron, P., Nitschke, W., Stetter, K.-O., Burlat, B., Guigliarelli, B., et al. (2003). [NiFe] hydrogenases from the hyperthermophilic bacterium these three broadly distributed genera harbor multiple copies of Group I hydrogenases for hydrogen uptake (Supplementary Table S1), likely exhibiting different hydrogen affinities, e.g., the Gotland Deep in the central Baltic Sea, where S. gotlandica was isolated from, is known to be a highly dynamic environment (Brettar and Rheinheimer, 1992; Grote et al., 2012; Labrenz et al., 2013). They also encode Group II hydrogenases, possibly involved in hydrogen sensing or energy conversion at low hydrogen concentrations (Sievert et al., 2008b; Campbell et al., 2009). Additionally they harbor Group IV hydrogenases for hydrogen evolution, probably coupling with proton conversion in hydrothermal vents or with energy conversion through carbon fixation. However, unfortunately, there is no experimental evidence to provide a precise understanding of the distinct SQR and hydrogenase functions and their roles remain enigmatic in these groups. Hence, it will be essential to investigate the roles of the different types of SQRs and hydrogenases in these (and other epsilonproteobacterial) genera to better understand how they deal with distinct environmental conditions. This knowledge would also shed light on how the environmental conditions can shape species' physiology.

\section{Acknowledgments}

$\mathrm{YH}$ was financed through the equal opportunity funding of the MIN-faculty of the University of Hamburg. We wish to thank Jan Kuever for some fruitful discussion on sulfur metabolisms, specifically with respect to assimilatory sulfate reduction.

\section{Supplementary Material}

The Supplementary Material for this article can be found online at: http://journal.frontiersin.org/article/10.3389/fmicb. 2015.00989

Aquifex aeolicus: properties, function, and phylogenetics. Extremophiles 7, $145-157$.

Cai, L., Shao, M.-F., and Zhang, T. (2014). Non-contiguous finished genome sequence and description of Sulfurimonas hongkongensis sp. nov., a strictly anaerobic denitrifying, hydrogen- and sulfur-oxidizing chemolithoautotroph isolated from marine sediment. Stand. Genomic Sci. 9, 1302-1310. doi: $10.4056 /$ sigs. 4948668

Campbell, B. J., and Cary, S. C. (2004). Abundance of reverse tricarboxylic acid cycle genes in free-living microorganisms at deep-sea hydrothermal Vents. Appl. Environ. Microbiol. 70, 6282-6289. doi: 10.1128/AEM.70.10.62826289.2004

Campbell, B. J., Engel, A. S., Porter, M. L., and Takai, K. (2006). The versatile epsilon-proteobacteria: key players in sulphidic habitats. Nat. Rev. Microbiol. 4, 458-468. doi: 10.1038/nrmicro1414

Campbell, B. J., Smith, J. L., Hanson, T. E., Klotz, M. G., Stein, L. Y., Lee, C. K., et al. (2009). Adaptations to submarine hydrothermal environments exemplified by the genome of Nautilia profundicola. PLoS Genet. 5:e1000362. doi: 10.1371/journal.pgen.1000362

Chan, L.-K., Morgan-Kiss, R. M., and Hanson, T. E. (2009). Functional analysis of three sulfide:quinone oxidoreductase homologs in Chlorobaculum tepidum. J. Bacteriol. 191, 1026-1034. doi: 10.1128/JB.0 1154-08 
Ducluzeau, A.-L., Ouchane, S., and Nitschke, W. (2008). The $c b b_{3}$ oxidases are an ancient innovation of the domain bacteria. Mol. Biol. Evol. 25, 1158-1166. doi: 10.1093/molbev/msn062

Engel, A. S., Porter, M. L., Stern, L. A., Quinlan, S., and Bennett, P. C. (2004). Bacterial diversity and ecosystem function of filamentous microbial mats from aphotic (cave) sulfidic springs dominated by chemolithoautotrophic "Epsilonproteobacteria". FEMS Microbiol. Ecol. 51, 31-53. doi: 10.1016/j.femsec.2004.07.004

Fisher, C. R., Takai, K., and Le Bris, N. (2007). Hydrothermal vent ecosystems. Oceanography 20, 14-23. doi: 10.5670/oceanog. 2007.75

Foster, B. A., Thomas, S. M., Mahr, J. A., Renosto, F., Patel, H. C., and Segel, I. H. (1994). Cloning and sequencing of ATP sulfurylase from Penicillium chrysogenum. Identification of a likely allosteric domain. J. Biol. Chem. 269, 19777-19786.

Frias-Lopez, J., Zerkle, A. L., Bonheyo, G. T., and Fouke, B. W. (2002). Partitioning of bacterial communities between seawater and healthy, black band diseased, and dead coral surfaces. Appl. Environ. Microbiol. 68, 2214-2228. doi: 10.1128/AEM.68.5.2214-2228.2002

Friedrich, C. G., Bardischewsky, F., Rother, D., Quentmeier, A., and Fischer, J. (2005). Prokaryotic sulfur oxidation. Curr. Opin. Microbiol. 8, 253-259. doi: 10.1016/j.mib.2005.04.005

Frigaard, N.-U., and Dahl, C. (2008). "Sulfur metabolism in phototrophic sulfur bacteria," in Advances in Microbial Physiology, Vol. 54, ed. K. P. Robert (Waltham, MA: Academic Press), 103-200.

Gevertz, D., Telang, A. J., Voordouw, G., and Jenneman, G. E. (2000). Isolation and characterization of strains CVO and FWKO B, two novel nitrate-reducing, sulfide-oxidizing bacteria isolated from oil field brine. Appl. Environ. Microbiol. 66, 2491-2501. doi: 10.1128/AEM.66.6.2491-2501.2000

Giovannelli, D., Ferriera, S., Johnson, J., Kravitz, S., Pérez-Rodríguez, I., Ricci, J., et al. (2011). Draft genome sequence of Caminibacter mediatlanticus strain TB$2 \mathrm{~T}$, an epsilonproteobacterium isolated from a deep-sea hydrothermal vent. Stand. Genomic Sci. 5, 135-143. doi: 10.4056/sigs.2094859

Glaubitz, S., Lueders, T., Abraham, W.-R., Jost, G., Jürgens, K., and Labrenz, M. (2009). ${ }^{13} \mathrm{C}$-isotope analyses reveal that chemolithoautotrophic Gamma- and Epsilonproteobacteria feed a microbial food web in a pelagic redoxcline of the central Baltic Sea. Environ. Microbiol. 11, 326-337. doi: 10.1111/j.14622920.2008.01770.x

Gleeson, D. F., Williamson, C., Grasby, S. E., Pappalardo, R. T., Spear, J. R., and Templeton, A. S. (2011). Low temperature $S^{0}$ biomineralization at a supraglacial spring system in the Canadian High Arctic. Geobiology 9, 360-375. doi: 10.1111/j.1472-4669.2011.00283.x

Golovacheva, R., and Karavaiko, G. (1977). [Sulfobacillus, a new genus of thermophilic sporulating bacteria]. Mikrobiologiia 47, 815-822.

Grabowski, A., Nercessian, O., Fayolle, F., Blanchet, D., and Jeanthon, C. (2005). Microbial diversity in production waters of a low-temperature biodegraded oil reservoir. FEMS Microbiol. Ecol. 54, 427-443. doi: 10.1016/j.femsec.2005.05.007

Griesbeck, C., Hauska, G., and Schütz, M. (2000). "Biological sulfide oxidation: sulfide-quinone reductase (SQR), the primary reaction," in Recent Research Developments in Microbiology, Vol. 4, ed. S. G. Pandalai (Trivadrum: Research Signpost), 179-203.

Groenendaal, M. (1979). On sulphide and the distribution of Arenicola marina in a tidal mud flat in the Dutch Wadden Sea. Net. J. Sea Res. 13, 562-570. doi: 10.1016/0077-7579(79)90026-7

Grote, J., Jost, G., Labrenz, M., Herndl, G. J., and Jurgens, K. (2008). Epsilonproteobacteria represent the major portion of chemoautotrophic bacteria in sulfidic waters of pelagic redoxclines of the Baltic and Black Seas. Appl. Environ. Microbiol. 74, 7546-7551. doi: 10.1128/AEM.01186-08

Grote, J., Schott, T., Bruckner, C. G., Glockner, F. O., Jost, G., Teeling, H., et al. (2012). Genome and physiology of a model Epsilonproteobacterium responsible for sulfide detoxification in marine oxygen depletion zones. Proc. Natl. Acad. Sci. U.S.A. 109, 506-510. doi: 10.1073/pnas.1111262109

Guindon, S., and Gascuel, O. (2003). A simple, fast, and accurate algorithm to estimate large phylogenies by maximum likelihood. Syst. Biol. 52, 696-704. doi: 10.1080/10635150390235520

Hamilton, T. L., Jones, D. S., Schaperdoth, I., and Macalady, J. L. (2014). Metagenomic insights into $S(0)$ precipitation in a terrestrial subsurface lithoautotrophic ecosystem. Front. Microbiol. 5:756. doi: 10.3389/fmicb.2014.00756

Han, C., Kotsyurbenko, O., Chertkov, O., Held, B., Lapidus, A., Nolan, M., et al. (2012). Complete genome sequence of the sulfur compounds oxidizing chemolithoautotroph Sulfuricurvum kujiense type strain (YK-1T). Stand. Genomic Sci. 6, 94-103. doi: 10.4056/sigs.2456004

Han, Y., and Perner, M. (2014). The role of hydrogen for Sulfurimonas denitrificans' metabolism. PLoS ONE 9:e106218. doi: 10.1371/journal.pone.0106218

Headd, B., and Summers Engel, A. (2014). Biogeographic congruency among bacterial communities from terrestrial sulfidic springs. Front. Microbiol. 5:473. doi: $10.3389 /$ fmicb. 2014.00473

Hedderich, R., Klimmek, O., Kröger, A., Dirmeier, R., Keller, M., and Stetter, K. O. (1998). Anaerobic respiration with elemental sulfur and with disulfides. FEMS Microbiol. Rev. 22, 353-381. doi: 10.1021/bi3014399

Henneberger, R.M. (2008). The Microbial Diversity and Ecology of Selected Andesitic Hydrothermal Environment. Ph.D. thesis, Macquarie University, Sydney, NSW.

Hubert, C. R. J., Oldenburg, T. B. P., Fustic, M., Gray, N. D., Larter, S. R., Penn, K., et al. (2012). Massive dominance of Epsilonproteobacteria in formation waters from a Canadian oil sands reservoir containing severely biodegraded oil. Environ. Microbiol. 14, 387-404. doi: 10.1111/j.1462-2920.2011.02521.x

Hügler, M., Petersen, J. M., Dubilier, N., Imhoff, J. F., and Sievert, S. M. (2011). Pathways of carbon and energy metabolism of the epibiotic community associated with the deep-sea hydrothermal vent shrimp Rimicaris exoculata. PLoS ONE 6:e16018. doi: 10.1371/journal.pone.0016018

Hügler, M., Wirsen, C. O., Fuchs, G., Taylor, C. D., and Sievert, S. M. (2005) Evidence for autotrophic $\mathrm{CO}_{2}$ fixation via the reductive tricarboxylic acid cycle by members of the $\varepsilon$ subdivision of proteobacteria. J. Bacteriol. 187, 3020-3027. doi: 10.1128/JB.187.9.3020-3027.2005

Inagaki, F., Takai, K., Kobayashi, H., Nealson, K. H., and Horikoshi, K. (2003). Sulfurimonas autotrophica gen. nov., sp. nov., a novel sulfur-oxidizing $\varepsilon$-proteobacterium isolated from hydrothermal sediments in the Mid-Okinawa Trough. Int. J. Syst. Evol. Microbiol. 53, 1801-1805. doi: 10.1099/ijs.0.0 2682-0

Jansen, S., Walpersdorf, E., Werner, U., Billerbeck, M., Böttcher, M., and De Beer, D. (2009). Functioning of intertidal flats inferred from temporal and spatial dynamics of $\mathrm{O}_{2}, \mathrm{H}_{2} \mathrm{~S}$ and $\mathrm{pH}$ in their surface sediment. Ocean Dynam. 59, 317-332.

Kappler, U., and Dahl, C. (2001). Enzymology and molecular biology of prokaryotic sulfite oxidation. FEMS Microbiol. Lett. 203, 1-9. doi: 10.1111/j.15746968.2001.tb10813.x

Kiehlbauch, J., Brenner, D., Nicholson, M., Baker, C., Patton, C., Steigerwalt, A., et al. (1991). Campylobacter butzleri sp. nov. isolated from humans and animals with diarrheal illness. J. Clin. Microbiol. 29, 376-385.

Kodama, Y., and Watanabe, K. (2003). Isolation and characterization of a sulfuroxidizing chemolithotroph growing on crude oil under anaerobic conditions. Appl. Environ. Microbiol. 69, 107-112. doi: 10.1128/AEM.69.1.107-11 2.2003

Kodama, Y., and Watanabe, K. (2004). Sulfuricurvum kujiense gen. nov., sp. nov., a facultatively anaerobic, chemolithoautotrophic, sulfur-oxidizing bacterium isolated from an underground crude-oil storage cavity. Int. J. Syst. Evol. Microbiol. 54, 2297-2300. doi: 10.1099/ijs.0.63243-0

Labrenz, M., Grote, J., Mammitzsch, K., Boschker, H. T., Laue, M., Jost, G., et al. (2013). Sulfurimonas gotlandica sp. nov., a chemoautotrophic and psychrotolerant epsilonproteobacterium isolated from a pelagic redoxcline, and an emended description of the genus Sulfurimonas. Int. J. Syst. Evol. Microbiol. 63, 4141-4148. doi: 10.1099/ijs.0.048827-0

Larkin, M. A., Blackshields, G., Brown, N. P., Chenna, R., Mcgettigan, P. A., Mcwilliam, H., et al. (2007). Clustal W and Clustal X version 2.0. Bioinformatics 23, 2947-2948. doi: 10.1093/bioinformatics/btm 404

Li, B., Chen, Y., Liu, Q., Hu, S., and Chen, X. (2011). Complete genome analysis of Sulfobacillus acidophilus strain TPY, isolated from a hydrothermal vent in the Pacific ocean. J. Bacteriol. 193, 5555-5556. doi: 10.1128/JB.05684-11

Ludwig, W., Strunk, O., Westram, R., Richter, L., Meier, H., Yadhukumar, A., et al. (2004). ARB: a software environment for sequence data. Nucleic Acids Res. 32, 1363-1371. doi: 10.1093/nar/gkh293

Mammitzsch, K., Jost, G., and Jürgens, K. (2014). Impact of dissolved inorganic carbon concentrations and $\mathrm{pH}$ on growth of the chemolithoautotrophic 
epsilonproteobacterium Sulfurimonas gotlandica GD1T. MicrobiologyOpen 3, 80-88. doi: 10.1002/mbo3.153

Marchal, K., Sun, J., Keijers, V., Haaker, H., and Vanderleyden, J. (1998). A cytochrome $\mathrm{Cbb}_{3}$ (Cytochrome $c$ ) terminal oxidase in Azospirillum brasilense Sp7 supports microaerobic growth. J. Bacteriol. 180, 5689-5696.

Marcia, M., Ermler, U., Peng, G., and Michel, H. (2009). The structure of Aquifex aeolicus sulfide:quinone oxidoreductase, a basis to understand sulfide detoxification and respiration. Proc. Natl. Acad. Sci. U.S.A. 106, 9625-9630. doi: 10.1073/pnas.0904165106

Marcia, M., Ermler, U., Peng, G., and Michel, H. (2010). A new structure-based classification of sulfide:quinone oxidoreductases. Proteins 78, 1073-1083. doi: $10.1002 /$ prot.22665

McClung, C. R., Patriquin, D. G., and Davis, R. E. (1983). Campylobacter nitrofigilis sp. nov., a nitrogen-fixing bacterium associated with roots of Spartina alterniflora Loisel. Int. J. Syst. Bacteriol. 33, 605-612. doi: 10.1099/0020771333-3-605

Meuer, J., Kuettner, H. C., Zhang, J. K., Hedderich, R., and Metcalf, W. W. (2002). Genetic analysis of the archaeon Methanosarcina barkeri Fusaro reveals a central role for Ech hydrogenase and ferredoxin in methanogenesis and carbon fixation. Proc. Natl. Acad. Sci. U.S.A. 99, 5632-5637. doi: 10.1073/pnas.072615499

Meyer, J. L., and Huber, J. A. (2014). Strain-level genomic variation in natural populations of Lebetimonas from an erupting deep-sea volcano. ISME J. 8, 867-880. doi: 10.1038/ismej.2013.206

Miller, W. G., Parker, C. T., Rubenfield, M., Mendz, G. L., Wösten, M. M. S. M., Ussery, D. W., et al. (2007). The complete genome sequence and analysis of the Epsilonproteobacterium Arcobacter butzleri. PLoS ONE 2:e1358. doi: 10.1371/journal.pone. 0001358

Mouncey, N. J., and Kaplan, S. (1998). Oxygen regulation of the $c c o N$ gene encoding a component of the $c b b_{3}$ oxidase in Rhodobacter sphaeroides $2.4 .1^{T}$ : involvement of the FnrL Protein. J. Bacteriol. 180, 2228-2231.

Nakagawa, S., Takai, K., Inagaki, F., Chiba, H., Ishibashi, J.-I., Kataoka, S., et al. (2005a). Variability in microbial community and venting chemistry in a sediment-hosted backarc hydrothermal system: impacts of subseafloor phase-separation. FEMS Microbiol. Ecol. 54, 141-155. doi: 10.1016/j.femsec.2005.03.007

Nakagawa, S., Takai, K., Inagaki, F., Hirayama, H., Nunoura, T., Horikoshi, K., et al. (2005b). Distribution, phylogenetic diversity and physiological characteristics of epsilon-Proteobacteria in a deep-sea hydrothermal field. Environ. Microbiol. 7, 1619-1632. doi: 10.1111/j.1462-2920.2005.00856.x

Nakagawa, S., Takai, K., Inagaki, F., Horikoshi, K., and Sako, Y. (2005c). Nitratiruptor tergarcus gen. nov., sp. nov. and Nitratifractor salsuginis gen. nov., sp. nov., nitrate-reducing chemolithoautotrophs of the epsilonProteobacteria isolated from a deep-sea hydrothermal system in the MidOkinawa Trough. Int. J. Syst. Evol. Microbiol. 55, 925-933. doi: 10.1099/ijs.0. 63480-0

Nakagawa, S., and Takaki, Y. (2009). "Nonpathogenic Epsilonproteobacteria," in Ecyclopedia of Life Sciences. Chichester: John Wiley \& Sons, Ltd. doi: 10.1002/9780470015902.a0021895

Nakagawa, S., Takaki, Y., Shimamura, S., Reysenbach, A. L., Takai, K., and Horikoshi, K. (2007). Deep-sea vent e-proteobacterial genomes provide insights into emergence of pathogens. Proc. Natl. Acad. Sci. U.S.A. 104, 12146-12150. doi: 10.1073/pnas.0700687104

Neumann, S., Wynen, A., Trüper, H., and Dahl, C. (2000). Characterization of the cys gene locus from Allochromatium vinosum indicates an unusual sulfate assimilation pathway. Mol. Biol. Rep. 27, 27-33. doi: 10.1023/A:10070584 21714

Noguchi, K., Riggins, D. P., Eldahan, K. C., Kitko, R. D., and Slonczewski, J. L. (2010). Hydrogenase-3 contributes to anaerobic acid resistance of Escherichia coli. PLoS ONE 5:e10132. doi: 10.1371/journal.pone.0010132

Palmer, T., and Berks, B. C. (2012). The twin-arginine translocation (Tat) protein export pathway. Nat. Rev. Micro. 10, 483-496. doi: 10.1038/nrmicro2814

Park, S.-J., Ghai, R., Martín-Cuadrado, A.-B., Rodríguez-Valera, F., Jung, M.Y., Kim, J.-G., et al. (2012). Draft genome sequence of the sulfur-oxidizing bacterium "Candidatus Sulfurovum sediminum" AR, which belongs to the Epsilonproteobacteria. J. Bacteriol. 194, 4128-4129. doi: 10.1128/JB.0 0741-12
Perner, M., Gonnella, G., Hourdez, S., Böhnke, S., Kurtz, S., and Girguis, P. (2013a). In-situ chemistry and microbial community compositions in five deepsea hydrothermal fluid samples from Irina II in the Logatchev field. Environ. Microbiol. 15, 1551-1560. doi: 10.1111/1462-2920.12038

Perner, M., Hansen, M., Seifert, R., Strauss, H., Koschinsky, A., and Petersen, S. (2013b). Linking geology, fluid chemistry, and microbial activity of basalt- and ultramafic-hosted deep-sea hydrothermal vent environments. Geobiology 11, 340-355. doi: 10.1111/gbi.12039

Pham, V. H., Yong, J.-J., Park, S.-J., Yoon, D.-N., Chung, W.-H., and Rhee, S.-K. (2008). Molecular analysis of the diversity of the sulfide : quinone reductase (sqr) gene in sediment environments. Microbiology 154, 3112-3121. doi: $10.1099 /$ mic. $0.2008 / 018580-0$

Pitcher, R. S., and Watmough, N. J. (2004). The bacterial cytochrome $c b b_{3}$ oxidases. BBA-Bioenergetics 1655, 388-399. doi: 10.1016/j.bbabio.2003.09.017

Potter, L., Angove, H., Richardson, D., and Cole, J. (2001). Nitrate reduction in the periplasm of gram-negative bacteria. Adv. Microb. Physiol. 45, 51-112. doi: 10.1016/S0065-2911(01)45002-8

Prabagaran, S. R., Manorama, R., Delille, D., and Shivaji, S. (2007). Predominance of Roseobacter, Sulfitobacter, Glaciecola and Psychrobacter in seawater collected off Ushuaia, Argentina, Sub-Antarctica. FEMS Microbiol. Ecol. 59, 342-355.

Preisig, O., Anthamatten, D., and Hennecke, H. (1993). Genes for a microaerobically induced oxidase complex in Bradyrhizobium japonicum are essential for a nitrogen-fixing endosymbiosis. Proc. Natl. Acad. Sci. U.S.A. 90, 3309-3313. doi: 10.1073/pnas.90.8.3309

Rajagopalan, K. V., and Johnson, J. L. (1992). The pterin molybdenum cofactors. J. Biol. Chem. 267, 10199-10202.

Reysenbach, A.-L., Liu, Y., Banta, A. B., Beveridge, T. J., Kirshtein, J. D., Schouten, S., et al. (2006). A ubiquitous thermoacidophilic archaeon from deep-sea hydrothermal vents. Nature 442, 444-447. doi: 10.1038/nature04921

Shahak, Y., and Hauska, G. (2008). "Sulfide oxidation from cyanobacteria to humans: sulfide-quinone oxidoreductase (SQR)," in Sulfur Metabolism in Phototrophic Organisms, Vol. 27, eds C. Dahl, D. Knaff, and T. Leustek (Amsterdam: Springer), 319-335.

Shao, M., Zhang, T., and Fang, H. H. P. (2009). Autotrophic denitrification and its effect on metal speciation during marine sediment remediation. Water Res. 43, 2961-2968. doi: 10.1016/j.watres.2009.04.016

Shibata, H., and Kobayashi, S. (2006). Characterization of a HMT2-like enzyme for sulfide oxidation from Pseudomonas putida. Can. J. Microbiol. 52, 724-730. doi: 10.1139/w06-022

Sievert, S. M., Hügler, M., Taylor, C., and Wirsen, C. (2008a). "Sulfur oxidation at deep-sea hydrothermal vents," in Microbial Sulfur Metabolism, eds C. Dahl and C. Friedrich (Berlin: Springer), 238-258.

Sievert, S. M., Scott, K. M., Klotz, M. G., Chain, P. S. G., Hauser, L. J., Hemp, J., et al. (2008b). Genome of the epsilonproteobacterial chemolithoautotroph Sulfurimonas denitrificans. Appl. Environ. Microbiol. 74, 1145-1156. doi: 10.1128/AEM.01844-07

Sikorski, J., Lapidus, A., Copeland, A., Glavina Del Rio, T., Nolan, M., Lucas, S., et al. (2010a). Complete genome sequence of Sulfurospirillum deleyianum type strain (5175T). Stand. Genomic Sci. 2, 149-157. doi: 10.4056/sigs.671209

Sikorski, J., Munk, C., Lapidus, A., Ngatchou Djao, O. D., Lucas, S., Glavina Del Rio, T., et al. (2010b). Complete genome sequence of Sulfurimonas autotrophica type strain (OK10T). Stand. Genomic Sci. 3, 194-202. doi: 10.4056/sigs.1173118

Smith, J. L., Campbell, B. J., Hanson, T. E., Zhang, C. L., and Cary, S. C. (2008). Nautilia profundicola sp. nov., a thermophilic, sulfur-reducing Epsilonproteobacterium from deep-sea hydrothermal vents. Int. J. Syst. Evol. Microbiol. 58, 1598-1602. doi: 10.1099/ijs.0.65435-0

Snaidr, J., Amann, R., Huber, I., Ludwig, W., and Schleifer, K. H. (1997). Phylogenetic analysis and in situ identification of bacteria in activated sludge. Appl. Environ. Microbiol. 63, 2884-2896.

Stolz, J. F., Ellis, D. J., Blum, J. S., Ahmann, D., Lovley, D. R., and Oremland, R. S. (1999). Sulfurospirillum barnesii sp. nov. and Sulfurospirillum arsenophilum sp. nov., new members of the Sulfurospirillum clade of the epsilon-proteobacteria. Int. J. Syst. Bacteriol. 49, 1177-1180. doi: 10.1099/00207713-49-3-1177

Takai, K., Campbell, B. J., Cary, S. C., Suzuki, M., Oida, H., Nunoura, T., et al. (2005). Enzymatic and genetic characterization of carbon and energy metabolisms by deep-sea hydrothermal chemolithoautotrophic isolates 
of Epsilonproteobacteria. Appl. Environ. Microbiol. 71, 7310-7320. doi: 10.1128/AEM.71.11.7310-7320.2005

Takai, K., Suzuki, M. T., Nakagawa, S., Miyazaki, M., Suzuki, Y., Inagaki, F., et al. (2006). Sulfurimonas paralvinellae sp. nov., a novel mesophilic, hydrogenand sulfur-oxidizing chemolithoautotroph within the Epsilonproteobacteria isolated from a deep-sea hydrothermal vent polychaete nest, reclassification of Thiomicrospira denitrificans as Sulfurimonas denitrificans comb. nov. and emended description of the genus Sulfurimonas. Int. J. Syst. Evol. Microbiol. 56, 1725-1733.

Tamura, K., Stecher, G., Peterson, D., Filipski, A., and Kumar, S. (2013). MEGA6: molecular evolutionary genetics analysis version 6.0. Mol. Biol. Evol. 30, 2725-2729. doi: 10.1093/molbev/mst197

Tan, B., and Foght, J. (2014). Draft genome sequences of Campylobacterales (Epsilonproteobacteria) obtained from methanogenic oil sands tailings pond metagenomes. Genome Announc. 2, e1034-14. doi: 10.1128/genomeA.01034-14

Timmer-Ten Hoor, A. (1975). A new type of thiosulphate oxidizing, nitrate reducing microorganism: Thiomicrospira denitrificans sp. nov. Net. J. Sea Res. 9, 344-351. doi: 10.1016/0077-7579(75)90008-3

Timmer-Ten Hoor, A. (1981). Cell yield and bioenergetics of Thiomicrospira denitrificans compared with Thiobacillus denitrificans. Antonie Van Leeuwenhoek 47, 231-243. doi: 10.1007/BF00403394

Ullrich, T. C., Blaesse, M., and Huber, R. (2001). Crystal structure of ATP sulfurylase from Saccharomyces cerevisiae, a key enzyme in sulfate activation. EMBO J. 20, 316-329. doi: 10.1093/emboj/20.3.316

Vande Weghe, J. G., and Ow, D. W. (1999). A fission yeast gene for mitochondrial sulfide oxidation. J. Biol. Chem. 274, 13250-13257. doi: $10.1074 /$ jbc. 274.19 .13250

Vetriani, C., Voordeckers, J. W., Crespo-Medina, M., O’brien, C. E., Giovannelli, D., and Lutz, R. A. (2014). Deep-sea hydrothermal vent Epsilonproteobacteria encode a conserved and widespread nitrate reduction pathway (Nap). ISME J. 8, 1510-1521. doi: 10.1038/ismej.2013.246

Vignais, P. M., and Billoud, B. (2007). Occurrence, classification, and biological function of hydrogenases: an overview. Chem. Rev. 107, 4206-4272. doi: $10.1021 / \mathrm{cr} 050196 \mathrm{r}$

Voordeckers, J. W., Starovoytov, V., and Vetriani, C. (2005). Caminibacter mediatlanticus sp. nov., a thermophilic, chemolithoautotrophic, nitrateammonifying bacterium isolated from a deep-sea hydrothermal vent on the Mid-Atlantic Ridge. Int. J. Syst. Evol. Microbiol. 55, 773-779. doi: 10.1099/ijs.0.63430-0
Voordouw, G., Armstrong, S. M., Reimer, M. F., Fouts, B., Telang, A. J., Shen, Y., et al. (1996). Characterization of 16S rRNA genes from oil field microbial communities indicates the presence of a variety of sulfate-reducing, fermentative, and sulfide-oxidizing bacteria. Appl. Environ. Microbiol. 62, 1623 1629.

Watanabe, K., Kodama, Y., Syutsubo, K., and Harayama, S. (2000). Molecular characterization of bacterial populations in petroleum-contaminated groundwater discharged from underground crude oil storage cavities. Appl. Environ. Microbiol. 66, 4803-4809. doi: 10.1128/AEM.66.11.4803-480 9.2000

Wirsen, C. O., Sievert, S. M., Cavanaugh, C. M., Molyneaux, S. J., Ahmad, A., Taylor, L. T., et al. (2002). Characterization of an autotrophic sulfide-oxidizing marine Arcobacter sp. that produces filamentous sulfur. Appl. Environ. Microbiol. 68, 316-325. doi: 10.1128/AEM.68.1.316-325.2002

Wolfe, R. S., and Penning, N. (1977). Reduction of sulfur by spirillum 5175 and syntrophism with Chlorobium. Appl. Environ. Microbiol. 33, 427-433.

Yagi, J. M., Neuhauser, E. F., Ripp, J. A., Mauro, D. M., and Madsen, E. L. (2009). Subsurface ecosystem resilience: long-term attenuation of subsurface contaminants supports a dynamic microbial community. ISME J. 4, 131-143. doi: 10.1038/ismej.2009.101

Zhang, M., Zhang, T., Shao, M. F., and Fang, H. H. P. (2009). Autotrophic denitrification in nitrate-induced marine sediment remediation and Sulfurimonas denitrificans-like bacteria. Chemosphere 76, 677-682. doi: 10.1016/j.chemosphere.2009.03.066

Zhang, Y., and Sievert, S. M. (2014). Pan-genome analyses identify lineage- and niche-specific markers of evolution and adaptation in Epsilonproteobacteria. Front. Microbiol. 5:110. doi: 10.3389/fmicb.2014.00110

Conflict of Interest Statement: The authors declare that the research was conducted in the absence of any commercial or financial relationships that could be construed as a potential conflict of interest.

Copyright (C) 2015 Han and Perner. This is an open-access article distributed under the terms of the Creative Commons Attribution License (CC BY). The use, distribution or reproduction in other forums is permitted, provided the original author(s) or licensor are credited and that the original publication in this journal is cited, in accordance with accepted academic practice. No use, distribution or reproduction is permitted which does not comply with these terms. 